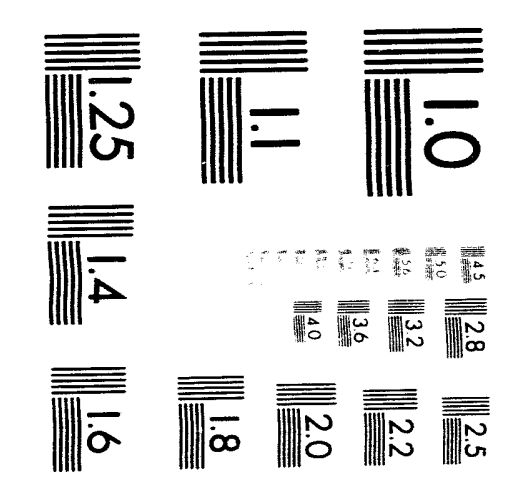



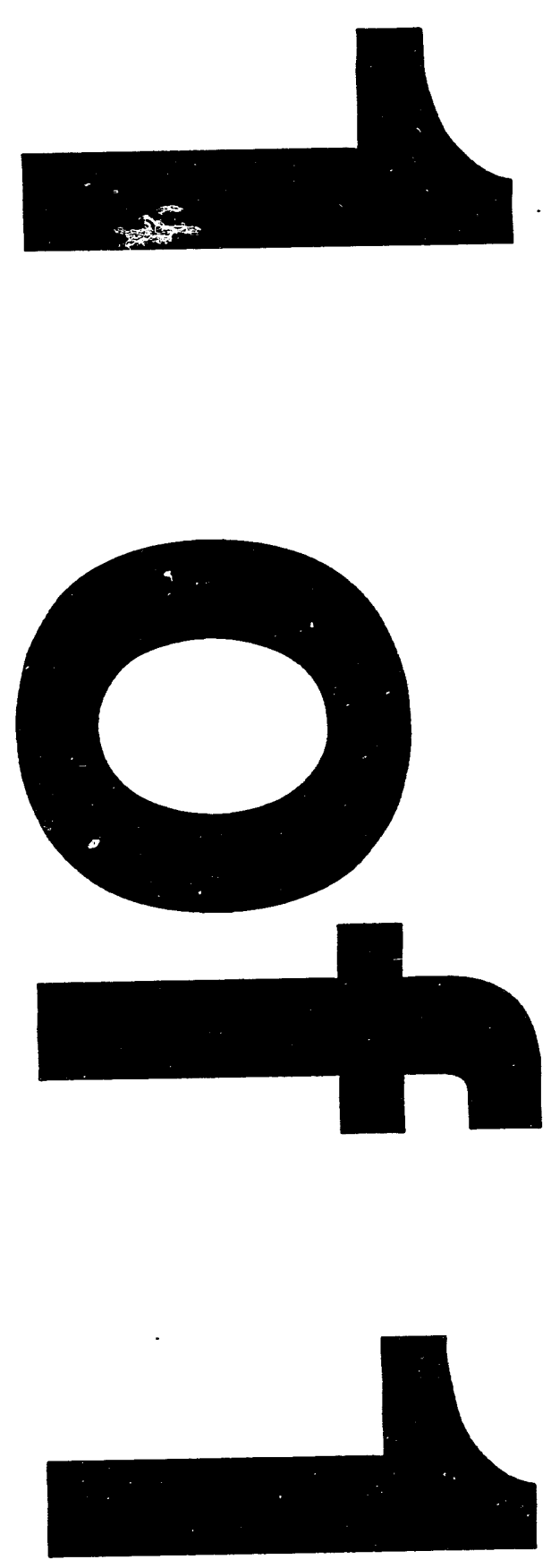


\title{
Control Algorithms for Effective Operation of Variable-Speed Wind Turbines*
}

\author{
W. A. Vachon \& Associates, Inc. \\ P. O. Box 149 \\ Manchester, MA 01944
}

Sandia Contract: 40-64()4

\begin{abstract}
This report describes a computer code, called ASYM, and provides results from its application in simulating the control of the 34-m Test Bed vertical-axis wind turbine (VAWT) in Bushland, Texas. The code synthesizes dynamic wind speeds on a second-bysecond basis in the time domain. The wind speeds conform to a predetermined spectral content governed by the hourly average wind speed that prevails at each hour of the simulation. The hourly average values are selected in a probabilistic sense through the application of Markov chains, but their cumulative frequency of occurrence conforms to a Rayleigh distribution that is governed by the mean annual wind speed of the site selected. The simulated wind speeds then drive a series of control algorithms that enable the code to predict key operational parameters such as number of annual starts and stops, annual energy production, and annual fatigue damage at a critically stressed joint on the wind turbine. This report also presents results from the application of ASYM that pertain to low wind speed cut-in and cut-out conditions and controlled operation near critical speed ranges that excite structural vibrations that can lead to accelerated fatigue damage.
\end{abstract}

* Prepared for Sandia National Lahoratories under Contract No. 40-64(04

MASTER

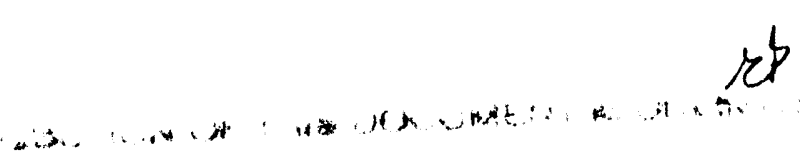




\subsection{INTRODUCTION}

\subsection{Background}

Over the past decade, developments in power electronics devices and high-power, rapid switching circuits have made possible the economic use of variable-speed constantfrequency (VSCF) wind turbines (WTs) [1]. The use of such machines allows designers to simplify the mechanical design of the machine, while placing a heavier burden on the electronic devices that regulate the frequency and quality of power being delivered by the WT. For example, drivetrain components may be made lighter and smaller if gustinduced transient loads can be inertially absorbed by a rotor speed change rather than reacting against a constant-speed rotor and being reflected as power swings. A VSCF WT also makes it possible for the operator to limit the maximum output power of a fixedpitch machine to a predetermined level by reducing the rotor speed and causing the airfoils to operate less efficiently. At a constant power output level, there is an associated increase in rotor torque as speed is reduced. However, the combination of an airfoil operating less efficiently, and the reduced rotor speed leads to overall cost savings in the mechanical structure. The benefits arise primarily because the WT structure can be lighter and is frequently designed more cost effectively since it does not have to absorb the full impact of gust-induced dynamics over most of its operating range of rotor speeds.

There are also associated increases in energy gathering efficiency associated with a VSCF WT. Variations in the average rotor speed in response to variations in average wind speed allow the WT rotor airfoils to operate more efficiently, while providing the opportunity for the rotor to dynamically respond to wind gusts (i.e., accelerate), thus gathering a small amount of additional kinetic energy. However, the key risk in operating a VSCF WT is that the machine's rotor speed can coincide with one of the many mechanical resonant vibrational frequencies of the WT and lead to accelerated material fatigue damage [1].

To study the use of VSCF generators, the original ASYM code $[2,3]$, containing time-domain simulations of a constant-speed rotor, was modified to allow the rotor speed to vary. Additional changes included the addition of inertia terms and a dynamic control algorithm that takes into account transient effects and rotor critical speed ranges in which operating time must be minimized to reduce structural fatigue. The code sums structural fatigue damage that occurs over the complete WT operating envelope. It also sums energy production and motoring energy either from normal operation or from rotor speed changes arising from generator-controlled braking ( $\mathrm{rpm}$ reductions) or generatoraugmented accelerations.

The code iakes into account most control parameters that are useful for governing WT cut-in and cut-out operation, while incorporating rotor speed control approaches that enable the WT to avoid or accelerate through rotor critical speed ranges. Passage through such rotor speed ranges can be controlled by sensing the actual rotor rpm and trends in the wind speed and altering generator torques as needed. ASYM is generally applicable to studies of the control tradeoffs associated with any stall-regulated wind turbine. 


\subsection{Historical Development of WT Control Studies}

Several of the publicly available analytical studies of WT supervisory controls have been fur mally supported by Sandia National Laboratories' (SNL's) wind energy research program funded by the U. S. Department of Energy (DOE). The original SNL studies estimated the sensitivity of WT life and energy production to choices of control parameters and operational conditions for constant-speed vertical-axis wind turbines (VAWTs) [2-6]. The parameters studied included:

(1) high and low wind speed cut-in and cut-out averaging methods and levels,

(2) post-shutdown wait times,

(3) WT sensitivity to cyclic stress loading, and

(4) site average wind speed and turbulence.

\subsection{Benefits of Simulation Code}

The ASYM code is useful for evaluating the effects of the following types of control considerations on WT fatigue life and energy production:

(1) The method of controlling startup from a non-operating condition, including averaging periods associated with wind speed or power for cut-in/cut-out decisions,

(2) The optimization of the controls to minimize fatigue life consumption over the entire WT operating envelope, but most importantly at high wind speeds,

(3) The overall benefits that arise from variable-speed operation versus fixedspeed operation,

(4) The rpm ranges over which variable-speed and constant-speed operation are permitted and when regenerative braking should be beneficially employed,

(5) The rpm range over which only coasting is permitted and when regenerative braking is appropriate during coasting conditions,

(6) The maximum permitted rate of change of rotor rpm (speed increases and decreases),

(7) The lowest rpm permitted before the WT is shut down, and

(8) The benefits to overall fatigue life and any energy production penalties that result from excluding operation over certain rpm ranges.

\subsection{Basis of Analytical Procedures}

The analytical procedures discussed in this report employ a time-domain wind simulator as the main program driver. The first step is to simulate the stochastic nature of wind on an hourly basis using Markov chains [4]. For each hourly average wind speed that is determined, the ASYM code subsequently simulates the high frequency, turbulent characteristics of the wind that are described in the frequency domain by the Kaimal 
spectrum [7,8] and summarized by Frost et al [9]. The frequency domain turbulence characteristics (i.e., spectra) are converted to the time domain by employing Veers' application of the Shinozuka method to develop second-by-second wind speeds. These values are used as input to the ASYM controller simulation, and drive the time-domain simulation of WT fatigue and energy production [10,11].

WT fatigue damage is evaluated by computing a damage rate per cycle and an annual damage density function [12]. These computations employ measured lab data on fully reversing cyclic stresses versus the number of cycles to failure (i.e., $\mathrm{S}-\mathrm{N}$ curves). These fatigue data for specific materials are employed in conjunction with Miner's linear cumulative damage rule [13] to estimate cumulative fatigue damage of specific, critically stressed components such as rotor blade joints. The fatigue calculation procedure is incorporated into a LIFE model developed by SNL $[14,15]$, an early version of which is included as a subroutine in ASYM.

Recent applications of ASYM have addressed the control of the SNL VSCF 34-m Test Bed WT located in Bushland, Texas $[16,17]$. The effort is an element of the long-term strategy for defining a control approach for the Test Bed unit under varying wind conditions, dynamic inputs, and material fatigue characteristics $[18,19]$. A key aspect of the work has been to minimize the WT operating time within critical rotor speed ranges that may lead to high fatigue damage. SNL, through an ongoing analytical and experimental effort, has predicted and measured the modal response of the 34-m VAWT mechanical structure and identified the critical speed ranges [20-22].

Ideally, wind turbine designers seek to avoid the presence of any critical structural resonance frequency that coincides with an integer multiple of the rotor drive frequency (range: 0.1 to $0.63 \mathrm{~Hz}$ ). Because this is not always possible, the control system for a VSCF unit must seek to avoid prolonged operation within critical speed ranges (CSRs) that would excite damaging structural resonances.

This report summarizes the status of the development of ASYM, with specific emphasis on low' wind speed cut-in/cut-out issues and approaches for controlling WT rotor speed in the vicinity of critical rpms. The results of simulations of the performance of the 34-m Test Bed VAWT are presented to illustrate key findings.

\subsection{TEST BED OPERATING ENVELOPE AND ASSOCIATED CONTROL LOGIC}

The operating envelope for a VSCF WT must be defined in terms of rotor speed, wind speed, and power, where the envelope for a constant-speed machine is defined only in terms of wind speed and power output. The maximum operating conditions for the three-dimensional operating envelope of the SNL Test Bed WT is shown as the solid line in Figure 1. At present the WT is allowed to rotate over a range of rotor speeds from 6 to $38 \mathrm{rpm}$, where originally it was planned to operate up to $40 \mathrm{rpm}$. As discussed later in this report, SNL tests have identified a rotor critical structural resonance that will receive excitation in the rotor speed range of 39.5 to $42.0 \mathrm{rpm}$, and operation in that $\mathrm{rpm}$ range must be precluded to minimize fatigue damage.

The general features of ASYM have been summarized in previous papers and reports referenced above. The key element of ASYM is the specific definition of the 


\section{Metre VAWT Test Bed}

\section{Variable Speed Power Surface and Low Wind Speed Control}

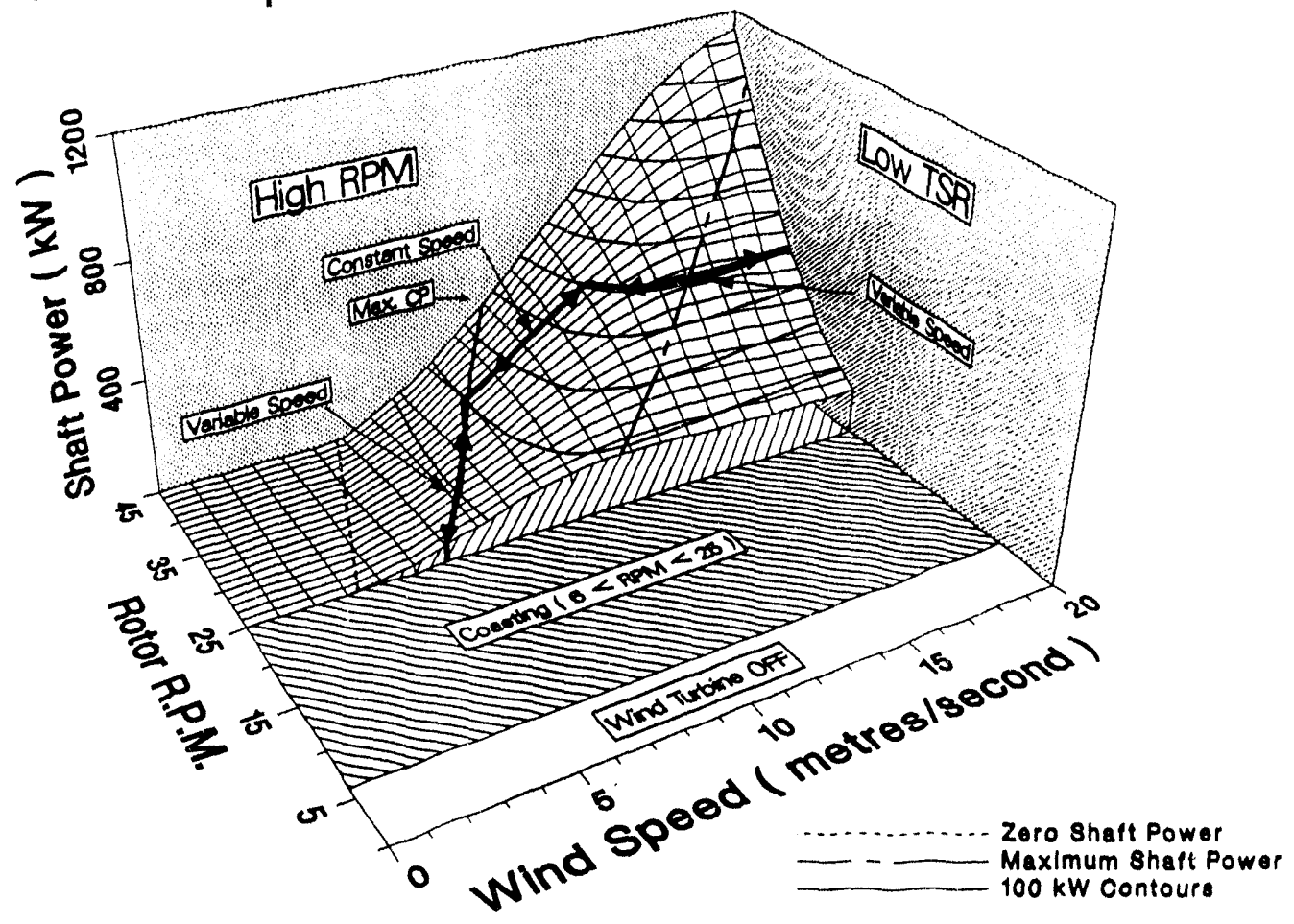

Figure 1. Operating Envelope of SNL's 34-m Test Bed VAWT 
dynamic controller logic that simulates the detailed actions of the WT on a second-bysecond basis. This section briefly discusses the program logic for a VSCF WT controller that simulates the expected dynamic behavior and desired control characteristics of the Test Bed at Bushland, Texas. Section 5 will describe a portion of the control logic that controls the rotor rpm near critical speeds that can excite structural resonances.

\subsection{Schematic Diagram of Controller}

Figure 2 is a schematic diagram that summarizes the overall elements in the ASYM control logic specific to a VSCF WT. The upper portion of the figure identifies the main decisions that the controller must make during on-line operation and coasting for speeds above $6 \mathrm{rpm}$. The lower portion of the diagram represents the decisions that are made by the controller when the WT is shut down and evaluating whether to start. Each portion of the control simulation is briefly described below.

Startup from Shutdown Condition. For WT startup, a simple moving-average power control algorithm is applied. This approach has been found to be the most efficient startup method for constant-speed machines [2]. In this stage of program development, the assumption is made that this is also true for variable-speed WTs.

For purposes of discussion it is assumed that simulations employ a 5-minute movingaverage power window width. The power values are based on the wind speed at the WT centerline and the generator output power derived from the variable-speed rotor power envelope shown in Figure 1. The rotor input power values are reduced to represent generator output according to equation (1). The application of equation (1) assumes that the rotor rpm would be controlled to equal the optimum rpm required to follow the operating envelope shown in Figure 1.

$$
\mathrm{P}_{\text {gen }}=\left[\mathrm{P}_{\text {rotor }}-\mathrm{P}_{\mathrm{GB}}-\mathrm{T}_{\mathrm{CB}} \Omega_{\mathrm{R}}\right]^{*} \eta_{\mathrm{gen}}
$$

In equation (1), $\mathrm{P}_{\mathrm{gen}}$ is the generator output power, $\mathrm{P}_{\text {rotor }}$ is the aerodynamic power to the rotor, $\mathrm{P}_{\mathrm{Gi}}$ is the constant power of $32 \mathrm{~kW}$ lost in the gearbox, $\mathrm{T}_{\mathrm{CB}}$ is the constant torque of $5 \mathrm{kNm}$ applied by the column bearings of the rotor, $\Omega_{R}$ is the rotor speed, and $\eta_{\text {gen }}$ is the efficiency of the generator itself (assumed to be 96 percent).

Once the startup criterion is satisfied, the WT will be motored up to $25 \mathrm{rpm}$ at an acceleration rate of $0.1 \mathrm{rpm} / \mathrm{s}$. A variation on this approach will be to motor to $6 \mathrm{rpm}$, and let the wind accelerate the rotor to higher rpms. It is not practical to let the wind provide all of the startup acceleration, because the Darrieus rotor is not viewed as a selfstarting WT (although it is self starting under certain conditions). Once the rotor is at 25 $\mathrm{rpm}$, the machine will go on line and the controller will adjust the precise rpm to follow the curve of maximum $C_{p}$ shown in Figure 1.

For subsequent operation at wind speeds that are insufficient to keep the rotor speed at or above $25 \mathrm{rpm}$, control reverts to a coasting algorithm to be described below. If, however, the rotor speed drops to a value below $6 \mathrm{rpm}$, due to insufficient windinduced torque, the machine will be shut down. It will then wait for a specified number of seconds (in the range of 60 to 300 seconds) before evaluating whether it should restart. When finally enabled, it will go through the normal low cut-in startup procedure. 


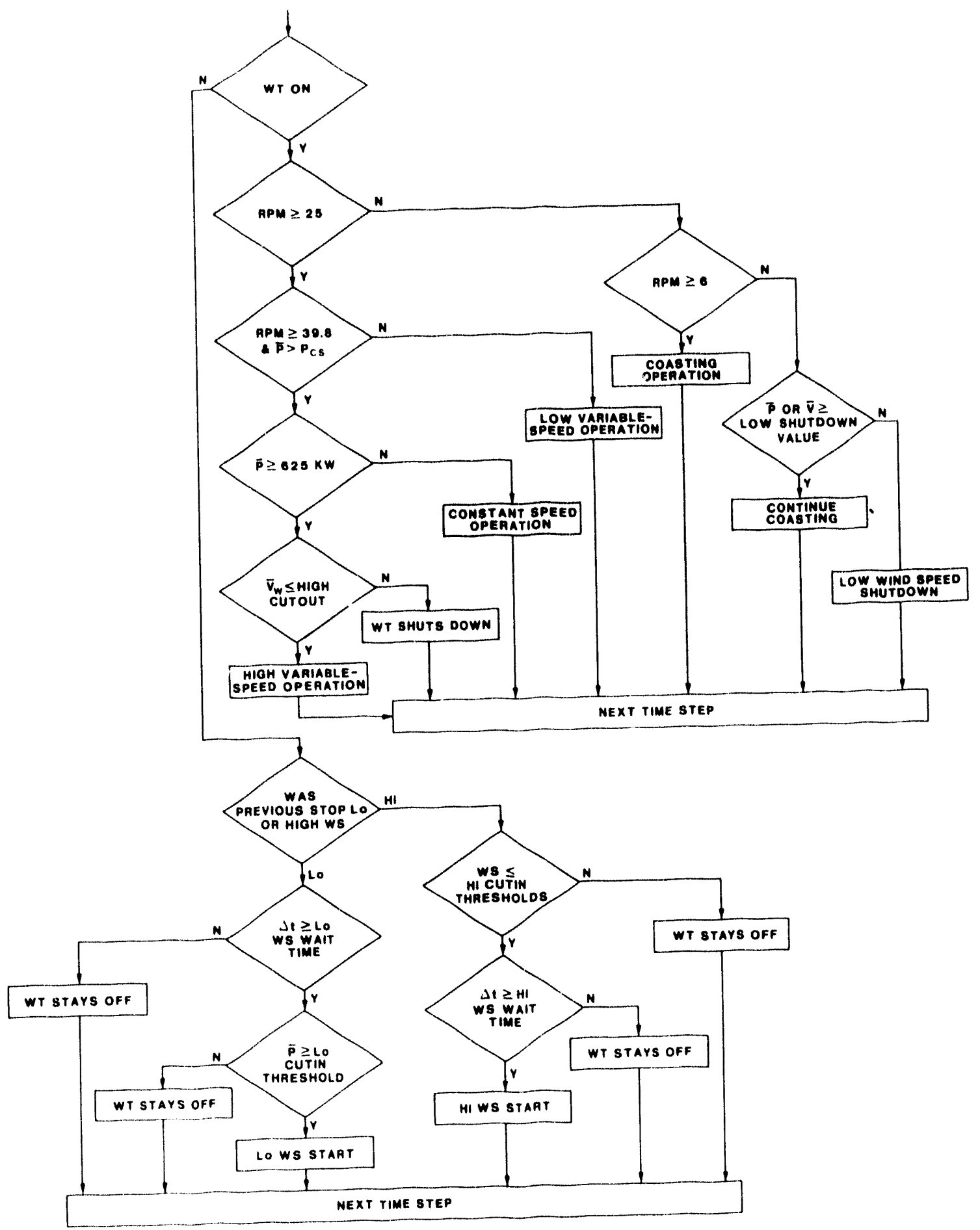

Figure 2. Schematic Representation of ASYM Controller Logic for Control of the 34-m Test Bed VAWT 
Coasting Algorithm. The initial control approach for marginal winds, where the rotor cannot maintain at least a $25-\mathrm{rpm}$ speed, is to allow the WT to coast between 6 and 25 $\mathrm{rpm}$. During coasting, the rotor rpm will be dictated by a balance of the applied loads - with no active control other than to avoid rpm's that excite critical structural resonances (discussed later).

Low Wind Speed, Variable-Speed Operation. For rotor speeds between 25 and $38 \mathrm{rpm}$ (wind speeds of from 6 to $10 \mathrm{~m} / \mathrm{s}$ ) the machine will be in the full variable-speed operating mode. Except for a need to avoid operation at rpm's that might excite critical structural resonances, the controller will endeavor to maintain an "optimum" rotor rpm that maximizes the power coefficient, $C_{p}$, at each wind speed. The precise manner in which the controller accommodates the WT response to gust dynanics and effects regeneration is discussed in a later section.

Constant-Speed Operation. In the presence of sufficient wind speeds, the rotor speed will eventually reach $38 \mathrm{rpm}$. At this point the machine will begin constant-speed operation, which will be maintained for wind speeds from 10 to $17 \mathrm{~m} / \mathrm{s}$. While in this mode, control is shifted to a power control mode similar to that of a conventional, constant-speed WT. As shown in Figure 2, the WT will begin this control mode if the rotor speed exceeds approximately $37.8 \mathrm{rpm}$ and the generator output exceeds the required value for constantspeed operation. This value is shown in the Figure 1 operating envelope, and is labeled as $\mathrm{P}_{\mathrm{cs}}$ in Figure 2.

Due to limitations on the dynamic response of the controller and rate of rpm change during regenerative braking (i.e., negative torque limitations), gust-induced rotor responses may lead to rotor speeds in excess of $38 \mathrm{rpm}$. This may occur during up gusts when control is "turning the corner" from VSCF to constant-speed operation (or the opposite direction) at either $10-$ or $17-\mathrm{m} / \mathrm{s}$ wind speeds. This feature in the controller requires additional design effort and verification during field tests. The final approach followed for control in this region may result from an optimization that considers the life of the gearbox and other WT elements that could be sensitive to rapid changes in generator torque.

High Wind Speed, Variable-Speed Operation. The WT will stay in the constant-speed mode of control until the generator power equals the maximum value permitted by the controller. The limit is dictated by either a maximum allowable torque in the drivetrain, thermal limits in the generator, or both. At this time that limit is specified as $625 \mathrm{~kW}$. For wind speeds above the value that produces $625 \mathrm{~kW}$, the WT will go into a higher variable-speed control mode. The rotor $\mathrm{rpm}$ will be reduced in a controlled manner to enable the airfoils to operate less efficiently (see Figure 1). Regenerative braking will be used wherever possible to reduce rotor speed during such a control mode. The lower rotor rpm at a constant power level will lead to slightly higher drivetrain torques. During periods of VSCF operation in the high wind speed range, for which the wind speed is dropping, the controller must overcome an unstable control condition in which lower wind speeds require the WT to operate at a higher rpm to follow the envelope. In such cases, the controller must reduce output power to obtain accelerating torque to speed up the rotor.

High Wind Speed Shutdown. At the high wind speed end of the operating envelope, the controller monitors two high wind speed moving averages (with variable window widths). First, there is a lower threshold value for high cut-out wind speed that has a larger 
window width, thus not bringing about abrupt shutdowns because it averages wind speed changes over a longer period. There is also a higher cut-out threshold value associated with a smaller window width that is aimed at shutting down the WT quickly if a sudden wind front or other meteorological event arrives that could suddenly damage a machine if it was not shut down quickly.

If either average exceeds prescribed levels, the machine will be shut down. Following a shutdown, the machine must wait for a period of time to be enabled, and then begin a start sequence. To minimize frequent high wind speed start/stop cycles that incur high fatigue damage, the moving average wind speed must be below a lower threshold level for high wind speed cut-in than it was for high wind speed cut-out. The thresholds can be varied and the effects studied. The controller will assure that during high wind speed cut-in the WT will be brought back on line at the proper state of rpm and power as dictated by the operating envelope.

\subsection{Constant Speed Machine}

If all rpm operating range values are specified as the same number in the input of the real controller or the ASYM simulation, the control is then assumed to be specified as a constant speed machine. For now, it is assumed that such a case holds only for a 38-rpm condition, but any rotor speed could be specified.

\subsection{Wind Speed Averaging Filter}

Due to scaling differences between the WT and wind sensors historically employed to develop wind spectra, the WT is expected to react more sluggishly to unsteady wind speeds (gusts and turbulence) than would be predicted by the application of typical wind spectra. Therefore, to simulate a wind turbine's lower-bandwidth response to wind speed changes, rapid variations in wind speeds are attenuated by the use of a moving average filter with an adjustable time constant. For most results to be discussed later in this report, a 10-second time constant filter is employed.

\subsection{Regenerative Braking}

There are three conditions under which the generator may apply added torques to the drivetrain to reduce its speed while generating additional energy. The first instance is when the generator acts as a speed modulating device to keep the rotor speed at an appropriate level to follow the operating envelope. Such control can occur anywhere within the WT operating envelope, but will generally occur during variable-speed operation. The second instance is when the generator acts as a brake to bring the rotor to a stop. Unless the generator torque is dramatically raised to stop the rotor under emergency conditions, or the WT experiences a significant number of high wind speed stops, analyses indicate that there is a negligible amount of energy produced by regenerative braking during stops. For low wind speed stops, the parasitic drag applied to the drivetrain from the column bearings and the gearbox will slow the rotor down at approximately the maximum-permitted rate under normal stop conditions. Therefore, there is little useful regenerative braking energy developed during stops.

The third instance in which regenerative braking is applied is during rotor speed control for rpm's near critical speeds. As discussed in Section 5, both motoring and regenerative braking are required for such control. 


\section{3.() SPLLD CONIROLILR I)ES(RIPTION}

\subsection{Rotor Dynamic Response}

A simplified model of the dynamic response of the WT has been assumed in modeling the W'T speed controller. The second order differential equation of WT rotational response is described by:

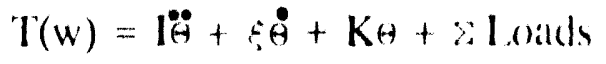

where

$$
\begin{aligned}
& \mathrm{T}(\mathrm{w})=\text { Wind-induced torgue } \\
& 1 \text { = The total rotary inertia of the rotor, gearbox, and generator (i.e., the } \\
& \Theta \quad=\text { Rotor rotational angle } \\
& \dot{\theta} \quad=d \omega / d t=\Omega_{R} \\
& \ddot{\theta} \quad=\mathrm{d}^{2}(\mathrm{H}) / \mathrm{d \textrm {L } ^ { 2 }}=\dot{\Omega}_{\mathrm{R}} \\
& \text { ह. = Drivetrain damping coefficient, and } \\
& \mathrm{K}=\text { Drivetrain torsional stiffiness coefficient. }
\end{aligned}
$$

for simplicity, it is assumed that drivetrain damping and stiffiness terms can be neglected because they are small compared to the terms that include inertia and the forcing function. Furihermore, torques, applied to the drivetrain from the generator, column bearings, and gearbox, are modeled as:

$$
\Sigma \text { Loads }=\frac{P_{g e n}+P_{(i) B} \cdot r_{g e n}}{\Omega_{R}}+T_{C H} \cdot \eta_{g c n}
$$

By substituting equation (3) into equation (2), and rearranging terms, the following first order differential equation in terms of rotor speed results:

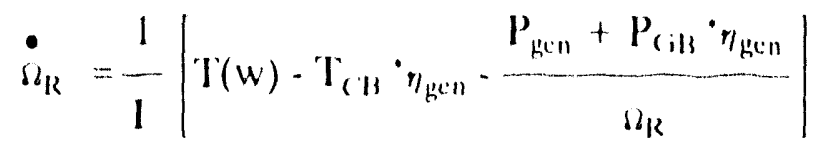

\subsection{Regenerative linergy Production}

For changes in drivetrain speed dictaled by a torgue imbalance, regenerattive energy can be derived from the rotational kinetic energy of the drivetrain as follows: 


$$
E_{R}=\frac{1}{2} \ln _{R}^{2}
$$

Therefore, regenerative energy can be calculated as follows:

$$
d E_{R}=I_{R} d n_{R}
$$

Thus, the program determines rotor speed, $n_{R}$, by integrating equation (6) with each time step. If high frequency torques due 10 wind turbulence, applied to the drivetrain, are larger than that required to follow the envelope specified by a filtered wind speed, then regenerative braking is applied to extract power from the turbulence. If the net drivetrain torque, summarized in equation (3), is less than that required to follow the operating envelope, the rpm will decrease. After a few time steps that include winds with magnitude less than the short-term average, the optimum (filtered) operating point associated with the envelope will be adjusted downward as well. The program monitors the total amount of energy produced by regenerative braking or by positive torques (i.e.. reduced generator output or motoring) necessary to increase rotor speed to follow the variable-speed portion of the operating envelope. Thus far, simulation experiences have shown that the majority of regenerative energy is derived from controller efforts $10 \mathrm{keep}$ the rotor rpm on the variable-speed power envelope shown in Figure 1 (i.e., at maximum $C_{p}$ ) as wind speeds drop.

\subsection{PRELIMINARY RESULTS ATLQW CUT.IN WIND SPEEDS}

This section provides the results from the application of a VSCF version of ASYM to the control of the VAWT Test Bed at low wind speed cut-in conditions. The analyses examine the sensitivity of the annual number of low wind speed start/stop cycles, the annual energy produced, and the fatigue life to the following control parameters:

(1) The low wind speed moving average power threshold level for WT start.

(2) The low wind speed moving average power averaging period (i.e., the moving average window width), and

(3) The wait time after stops before allowing the controller to reenable the WT for restart if the moving average power level criterion is satisfied.

Past studies have shown that the number of WT starts and stops plays an important role in determining both the life and the energy production of WTs [5,6]. ASYM was exercised to evaluate the sensitivity of the number of annual low wind speed start-stop cycles to the moving-average power turn-on threshold. Once the startup requirements of the moving-average power threshold are met, the WT brake will be released and the WT rotor will be motored up to $25 \mathrm{rpm}$, after which it is hoped that the machine will he able to enter the variable-speed control mode and generate useful power. However, if the start-up threshold is too low, wind-powered rotor torques will be too low to maintain an adequate $\mathrm{rpm}$ for variable-speed, powered operation. Thus, the rotor speed will drop. and frequently the rpm will drop so low that the machine will go off line. Thus, with a low power threshold setting, the WT will start and stop frequently-incurring the potential of substantial fatigue damage. At the same time, when it stops frequently, there will be a post-stop wait time during which the WT cannot be enabled to start-also leading. 
potentially, to lost cnergy. For VAWTs, there is also a small amount of motoring energy required for each restart that must be taken into account in the annual energy budget.

On the other hand, if the low wind speed turn-on threshold is set too high, the machine will start less frequently, but when it does start it will generally stay on line. For high threshold values, though, substantial energy generation may be lost while the machine is off - waiting to satisfy a stringent turn-on criterion. Thus, conceptually there is an optimum moving average power level that maximizes annual energy production and minimizes fatigue damage. The best algorithm for low wind speed starts will be sensitive in (1) the fatigue damage incurred per stop/start cycle, (2) the moving average power threshold, (3) the moving average window width (WW) or averaging period, and (4) the post-stop wait time.

The simulatiors employ Rayleigh-distributed winds with annual average wind speeds of from 6 to $8 \mathrm{~m} / \mathrm{s}$ and a terrain roughness length scale $Z_{o}=0.1 \mathrm{~m}[9]$. This assumption for roughness is appropriate for a countryside with many wind breaks, resulting in moderate turbulence. The optimum value for both the cut-in and cut-out thresholds is expected to vary with annual average wind speed, wind turbulence, and other factors listed above. The effects of each parameter were simulated, and the preliminary results are discussed in the following paragraphs.

\section{I Moving siverage Power Level}

The moving average power level is a computed average equivalent output power that the W"I would generate according to its power curve, based on the prevailing wind peed. For many of the analyses discussed later, the moving average power level has been computed using a window width of 300 seconds. Thus, the average power level is derived in the linear average of the second-by-second output power levels that are appropriate for each wind speed (hased on the power curve or operating envelope) during the most recent 3(1)-second period. According to prior research at SNL [2], the moving average power algurithm produced approximately 1 percent more energy per year than three wher algorithms that included moving average and discrete average wind speed algurithms. Therefore, this approach has been followed in this research.

\subsection{Starts - Stops and Energy Production}

Figure 3 is a plot of the estimated number of annual low wind speed start-stop cycles as a function of cut-in power threshold, with annual average wind speed as a parameter. The estimates are associated with a 300 -second moving-average window width. a 120-second post-stop wait time, and a 250 -second start time to allow the rotor to accelerate from a stopped condition to $25 \mathrm{rpm}$ at the specified rate of $0.1 \mathrm{rpm} / \mathrm{sec}$. After that, it is hoped that the machine will generate useful power. Past tests at SNL have indicated the number of stress cycles during start/stops and the stress levels at critically stressed joints. By applying Miner's cumulative damage rule [13], the tests have indicated that approximately 200,000 such cycles would result in a failure at the joint. Thus, each start is assumed to consume 0.000005 of the life of the joint. 


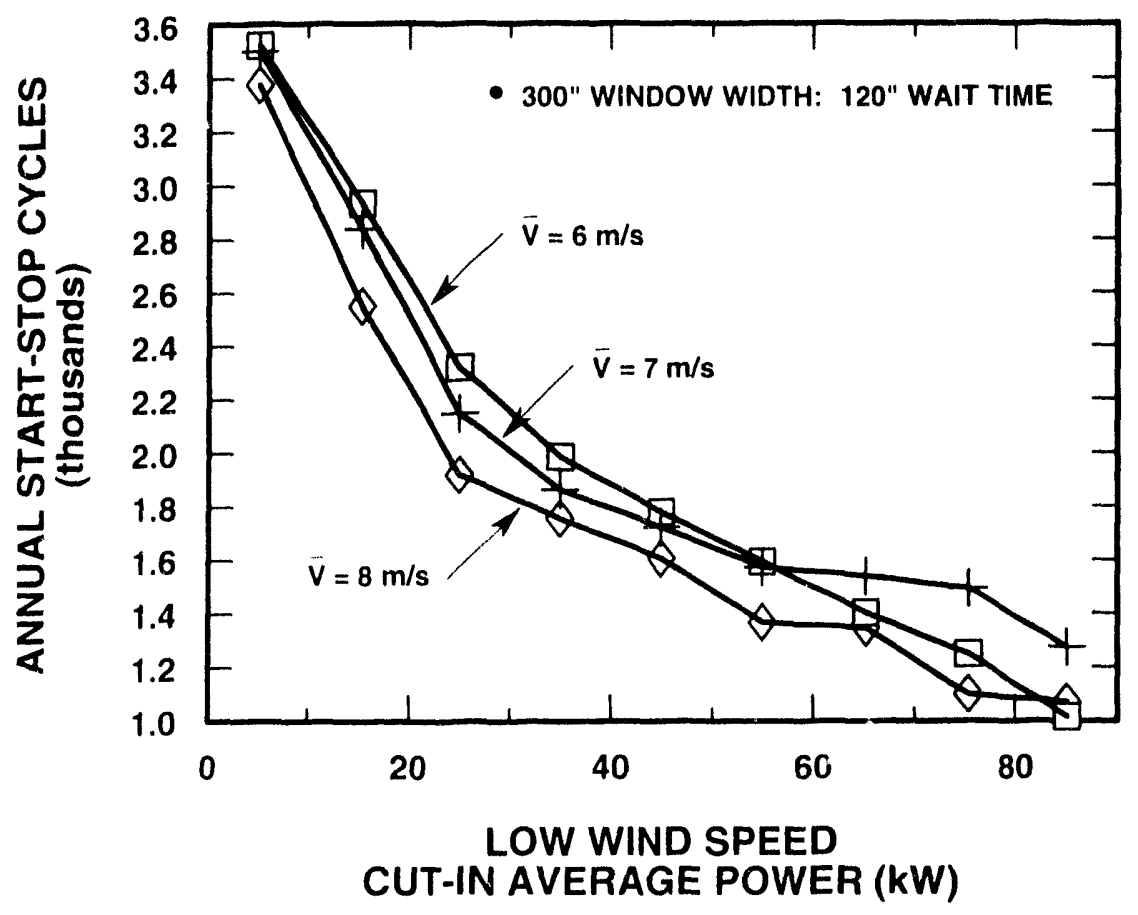

Figure 3. Variation of Low Wind Speed Start-Stop Cycles with Algorithm Low Cut-in Moving-Average Power Threshold

The results plotted in Figure 3 show the following:

(1) As expected, the lower the threshold level for turn on, the higher will be the number of annual start/stop cycles experienced, reaching as many as nearly 10 per day if the threshold is set at levels as low as approximately $10 \mathrm{~kW}$.

(2) For threshold levels of approximately $60 \mathrm{~kW}$ to $80 \mathrm{~kW}$, the curve is flatter and less sensitive to the cut-in threshold. These threshold levels are appealing and are expected to lead to approximately 3 to 4 start/stop cycles per day.

(3) The lower the wind speed, the more start/stop cycles the WT experiences. For threshold levels of 60 to $80 \mathrm{~kW}$, there may be as many as 25 to 35 percent more cycles for a $6-\mathrm{m} / \mathrm{s}$ site than for an $8-\mathrm{m} / \mathrm{s}$ site.

Further simulation results are plotted in Figures 4 and 5 in order to look at the sensitivity of the number of start/stop cycles to moving average window width, which was varied from 30 to 300 seconds. The results are specific to 7 - and $8-\mathrm{m} / \mathrm{s}$ sites, respectively. The plots, with shapes similar to those in Figure 3, indicate that: 


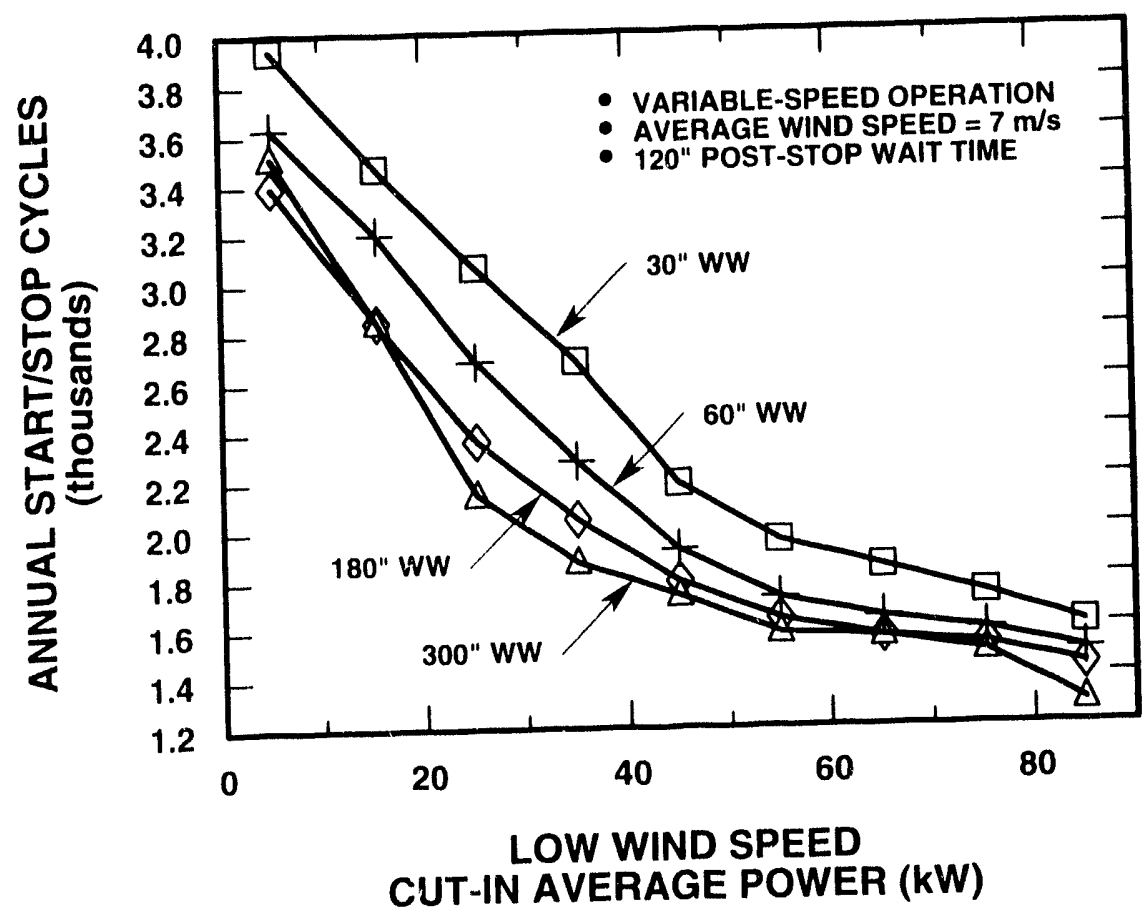

Figure 4. Variation of Annual Start/Stop Cycles with Low Cut-in Threshold and Moving Average Window Width at a $7-\mathrm{m} / \mathrm{s}$ Site

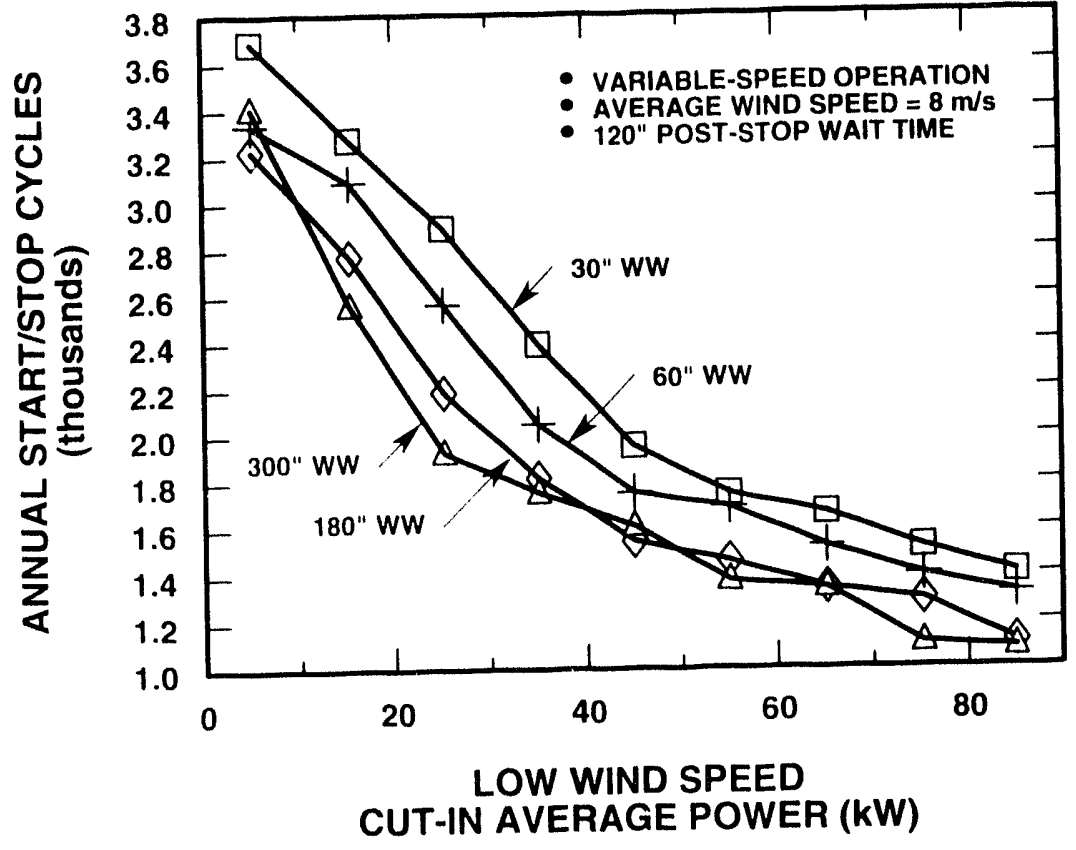

Figure 5. Variation of Annual Start/Stop Cycles with Low Cut-in Threshold and Moving Average Width at an $8-\mathrm{m} / \mathrm{s}$ Site 
(1) The longer the averaging window width, the lower the number of start/stop cycles, because the WT reacts more to long-term trends in the wind speed.

(2) The benefit of a longer window width is most pronounced for intermediate thresholds of approximately 25 to $35 \mathrm{~kW}$, where a 30-second window width leads to 50 percent more start/stop cycles than for a 300 -second window width. This effect is not easily explained. For promising threshold settings of 60 to 80 $\mathrm{kW}$, a 30 -second $W W$ leads to only 15 or 20 percent more cycles than a 300-second WW.

(3) A $7-\mathrm{m} / \mathrm{s}$ wind speed site leads to approximately 15 percent more start/stop cycles per year than an $8-\mathrm{m} / \mathrm{s}$ site.

\subsection{Annual Energy Production}

The variation of annual energy production with low wind speed cut-in threshold is plotted in Figure 6 for annual average wind speeds of $6-, 7-$, and $8-\mathrm{m} / \mathrm{s}$. The plots are for the specific case of a 300-second window width and a 120-second post-stop wait time. The results indicate that there is a clear optimum choice for cut-in threshold that maximizes energy production for the parameters selected. The curves for each annual average wind speed are similarly shaped and indicate an optimum threshold at a setting of approximately $25 \mathrm{~kW}$. As expected, the higher wind speed sites produce a higher percent of available energy. This is true because the winds are not near the low, or marginal, values as often - leading to a higher percentage of operational time and fewer start/stop cycles.

Several simulations were run in which the moving average window width (WW) and wait times were varied in order to study the effect of their value on annual average energy production. The results are plotted in Figures 7 through 10 . In Figures 7 and 8 , both the WW and post-stop wait times were varied for $7-$ and $8-\mathrm{m} / \mathrm{s}$ sites respectively. The other assumptions employed by ASYM are listed in the figures. The results indicate the following:

(1) The optimum moving average power turn-on threshold for 30 -second WW is approximately $55 \mathrm{~kW}$, or approximately twice as high as the optimum value of $25 \mathrm{~kW}$ for a 300 -second $\mathrm{WW}$.

(2) At the optimum low wind speed moving average power thresholds, there is a slight energy production benefit (less than 0.2 percent of available energy) that arises from the use of a 30-second WW (i.e, the square and plus symbols in Figures 7 and 8) compared to a 300-second WW (i.e., the diamond and triangle symbols).

(3) As shown in Figures 7 and 8, there is an even smaller energy production benefit (less than 0.1 percent) that arises from using a 120 -second post-stop wait time vs. a 240 -second value. 


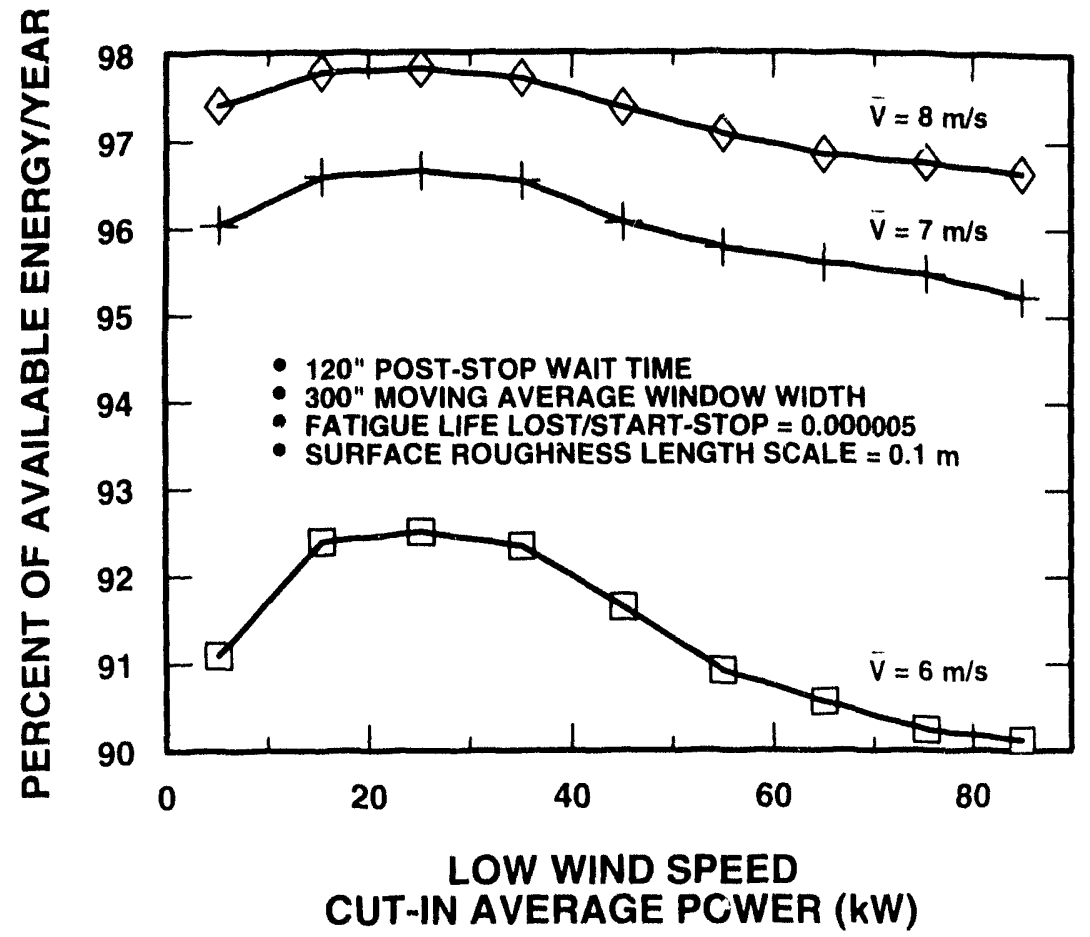

Figure 6. Estimated Annual Energy Production (Percent of Available) vs. Low Cut-in Power Threshold as a Function of Site Annual Average Wind Speed

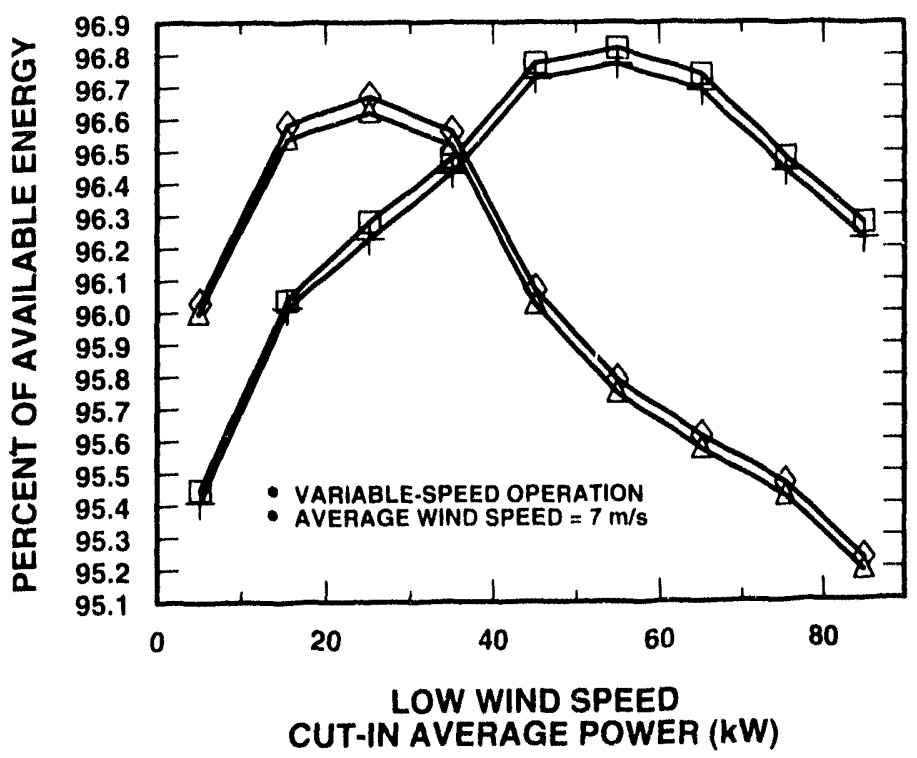

$$
\begin{array}{ll}
\square \text { 30" WW, 120" WAIT } & +30 " \text { "WW, 240" WAIT } \\
\diamond 30{ }^{\prime \prime} \text { WW, 120" WAIT } & \triangle 30{ }^{\prime \prime} W W, 240 " \text { WAIT }
\end{array}
$$

Figure 7. Variation in Energy Production as a Function of Low Wind Speed Cut-in Threshold for Two Settings for Moving Average Window Width and PostStop Wait Time $(7-\mathrm{m} / \mathrm{s}$ Site $)$ 


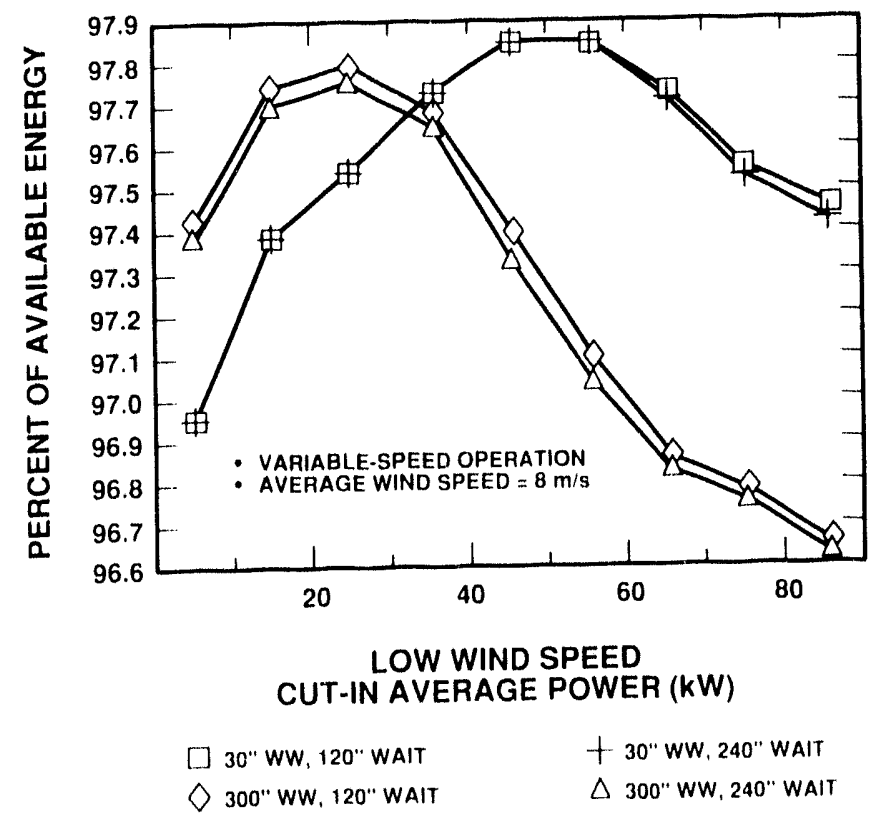
Figure 8. Variation in Energy Production as a Function of Low Wind Speed Cut-in
Threshold for Two Settings for Moving Average Window Width and PostStop Wait Time $(8-\mathrm{m} / \mathrm{s}$ Site)

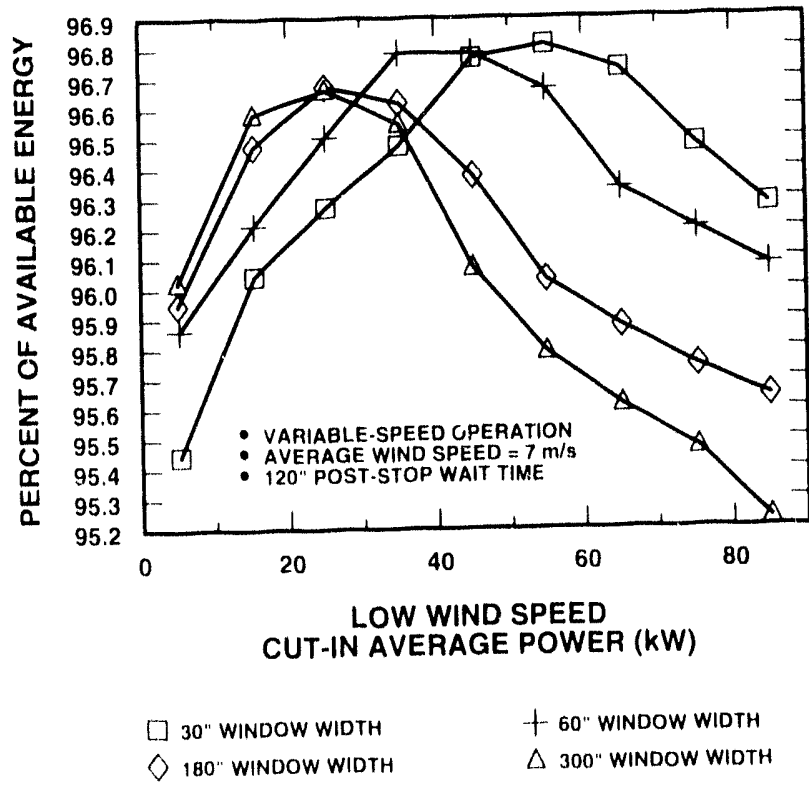

Figure 9. Variation in Energy Production as a Function of Low Wind Speed Cut-in Threshold for Various Settings for Moving Average Window Width, Assuming a Post-Wait Stop Time of 120 Seconds ( $7-\mathrm{m} / \mathrm{s}$ Site) 


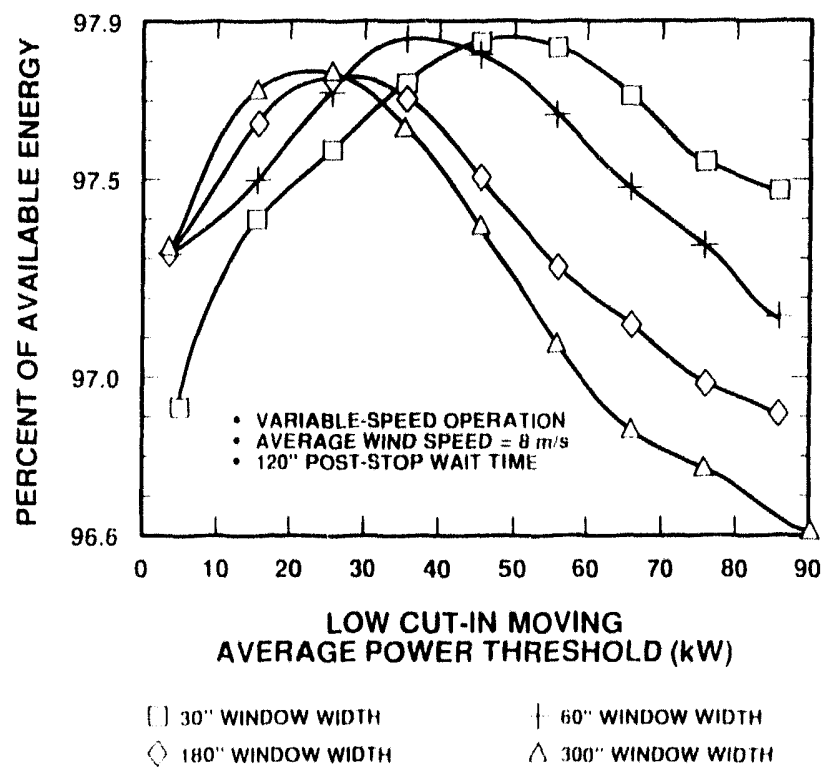

Figure 10. Variation in Energy Production as a Function of Low Wind Speed Cut-in Threshold for Various Settings for Moving Average Window Width, Assuming a Post-Wait Stop Time of 120 Seconds $(8-\mathrm{m} / \mathrm{s}$ Site)

(4) As observed earlier, approximately one percent less of the available energy is captured at a $7-\mathrm{m} / \mathrm{s}$ site compared to a site with an annual average wind speed of $8-\mathrm{m} / \mathrm{s}$.

The first observation arises because the higher threshold level for starts counteracts the effect of the short window width, and keeps the WT from starting too easily. The second and third observations are explainable from the fact that in each case the WT can come on line sooner, and thus operates longer. This feature protects the WT from frequent start/stop cycling and attendant losses of energy. The role of fatigue is, however, not addressed by the estimates shown. That question is discussed later.

To explore the above observations more clearly, additional simulations were run in which the window width was varied incrementally from 30 seconds to 300 seconds. The results, shown in Figures 9 and 10 for 7 - and $8-\mathrm{m} / \mathrm{s}$ sites respectively, show a uniform shift to slightly higher energy production with higher values of cut-in moving average power threshold that are associated with shorter values of window width (WW).

\subsection{Fatigue Life}

Low wind speed cut-in control algorithms are generally a very important issue in enhancing fatigue life, because so many of the hours associated with most wind spectra are in the vicinity of low wind speed cut-in values. The goal of the WT is to operate and generate energy, so it must be on line as often as practical- withont seriously compromising the machine's life. Thus, the role of ASYM is of key importance because it takes all factors into account and allows the designers and wind plant managers to make 
clear economic tradeoffs on these issues. For example, if the estimated WT fatigue life was found to be 15 years, but the plant managers know that they plan to replace the WT in 5 years with a better unit (or it is fully depreciated for tax purposes), they may conduct some simple economic studies to show that fatigue life is not important in the selection of control algorithms.

Figures 11 and 12 present the variation of estimated fatigue life as a function of the low cut-in moving-average power threshold for 7 - and $8 \mathrm{-m} / \mathrm{s}$ site respectively. The estimates are developed for a wind-stress function (WSF) of $0.28 \mathrm{RMS}(\mathrm{MPa}) /(\mathrm{m} / \mathrm{s})(40$ $\operatorname{RMS}(\mathrm{psi}) /(\mathrm{m} / \mathrm{s}))$ that is a typical value that might be found in a VAWT rotor fabricated of 6063-T6 aluminum [12]. The plots show the variation of life as a function of the moving average window width and the post-stop wait times. Figures 13 and 14 explore the sensitivity of the results in Figures 11 and 12 to more increments in window width, while holding constant the post-stop wait time at a value of 120 seconds.

The plots show the following:

(1) Shorter lives are found at low values of threshold power on all plots, resulting primarily from frequent start-stop cycles that consume life. The life consumed per start/stop cycle is identified in Figure 11.

(2) As expected, the longer moving average window widths produce greater fatigue lives because the WT is operating less (and generating less energy). However, the sensitivity of energy capture to WW is relatively small. The estimates show a factor of 10 increase in WW leads to an 8.5-percent increase in WT life, with only a 0.1 to 0.2 percent decrease in annual energy production (see Figures 7 and 8 ). If the amount of life lost per start/stop cycle (and other costs associated with generators and contactors) are taken into account, preliminary estimates indicate that a 300 -second moving average window width is preferred.

(3) There is essentially a zero difference in fatigue life between a 120-second and a 240-second post-stop wait time. This finding is consistent with the results shown in Figures 7.10 in which annual energy production was also found to be relatively insensitive to post-stop wait times. Thus, it can be concluded that a 120- second wait time (or shorter) is preferred because more energy is produced, but fatigue life is unaltered.

(4) Operation at a $7-\mathrm{m} / \mathrm{s}$ site leads to an expected life that is at least twice as long as for similar operation at a site with an annual average wind speed of $8-\mathrm{m} / \mathrm{s}$. As long as life is on the order of several years, this finding may be irrelevant to a wind park operator or manager.

\subsection{Conclusions Related to Low Cut-in Wind Speeds}

Based on the simulation results reported above, it is recommended that the following control parameters be applied as a means of producing nearly as much energy as possible, while not severely compromising fatigue damage: 


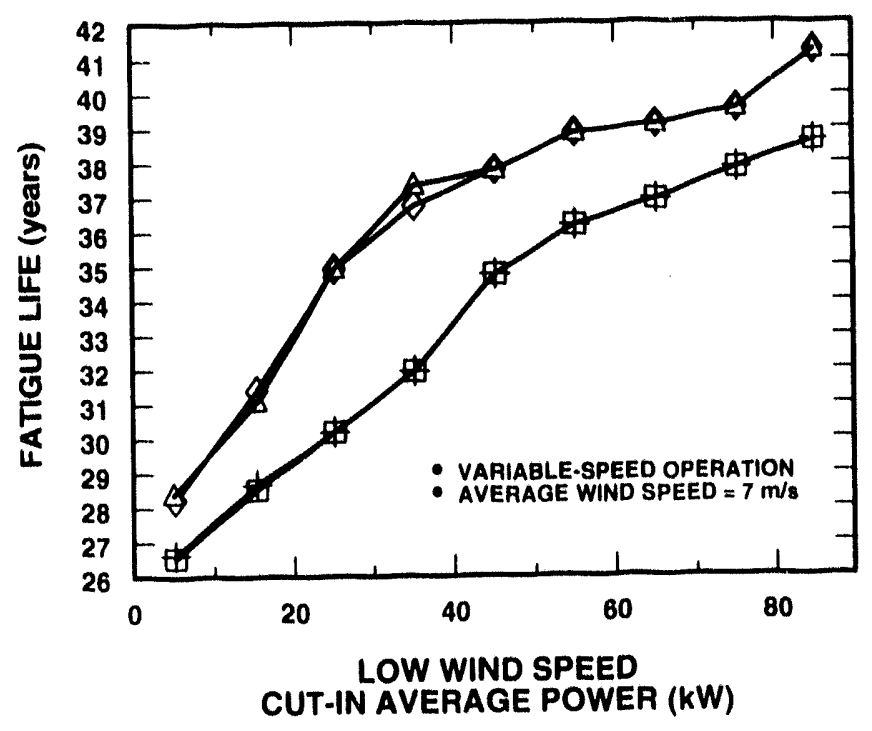

$\square$ 30" WW, 120" WAIT

$+30^{n}$ WW, 240" WAIT

$\diamond 300^{\prime \prime}$ WW, 120" WAIT

$\triangle 300 "$ WW, 240" WAIT

Figure 11. Variation in Fatigue Life as a Function of Low Wind Speed Cut-in Threshold for Two Settings for Moving Average Window Width and Post-Stop Wait Time $(7-\mathrm{m} / \mathrm{s}$ Site $)$

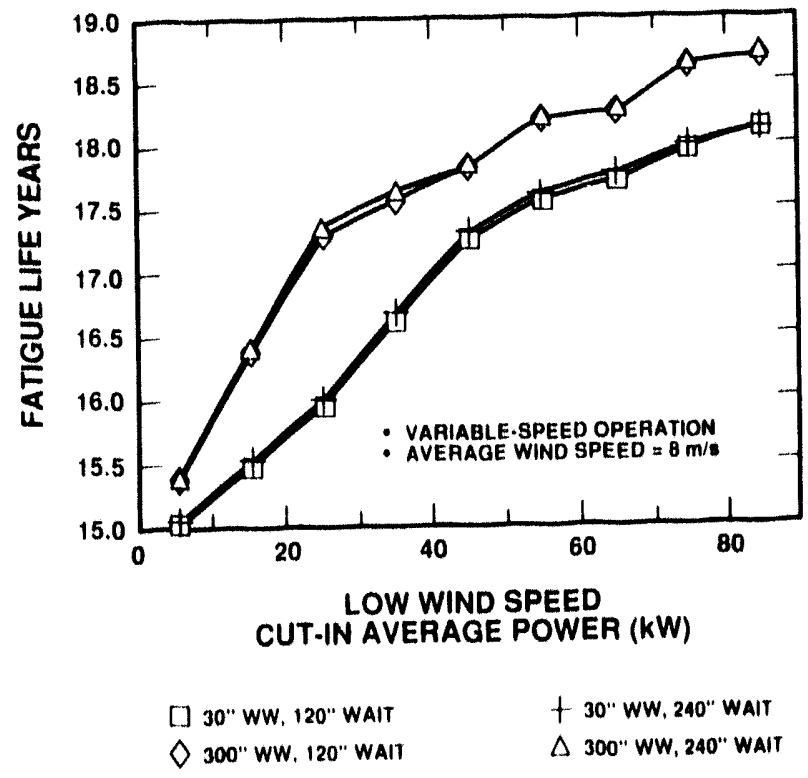

Figure 12. Variation in Fatigue Life as a Function of Low Wind Speed Cut-in Threshold for Two Settings for Moving Average Window Width and Post-Stop Wait Time $(8-\mathrm{m} / \mathrm{s}$ Site $)$ 


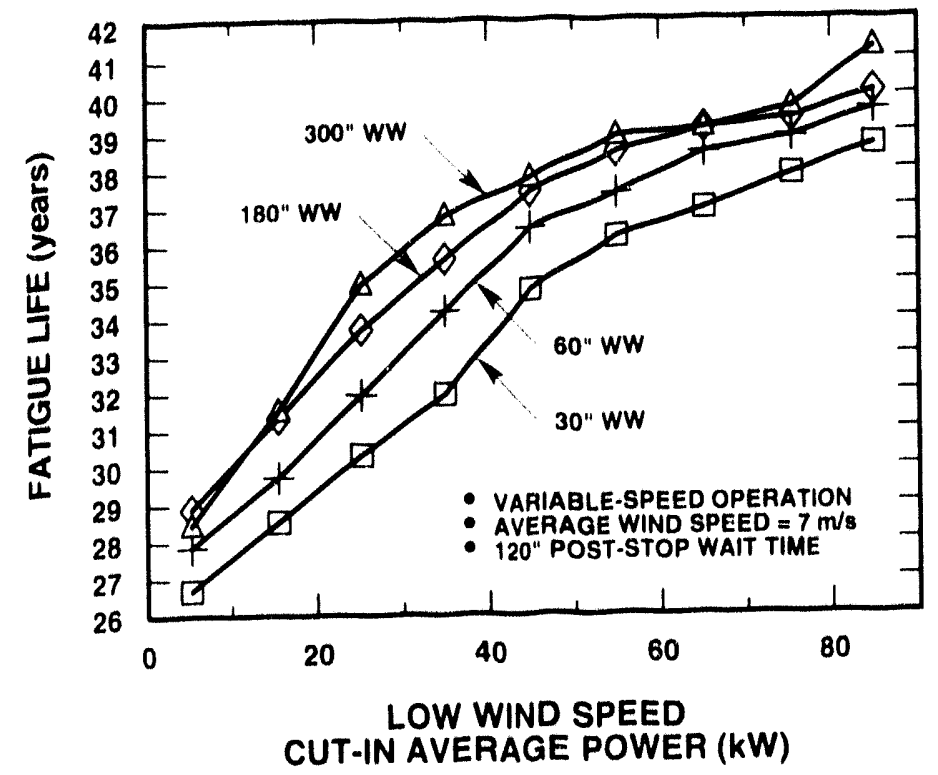

Figure 13. Variation in Fatigue Life as a Function of Low Wind Speed Cut-in Threshold for Various Settings for Moving Average Window Width, Assuming a PostStop Wait Time of 120 Seconds $(7-\mathrm{m} / \mathrm{s}$ Site $)$

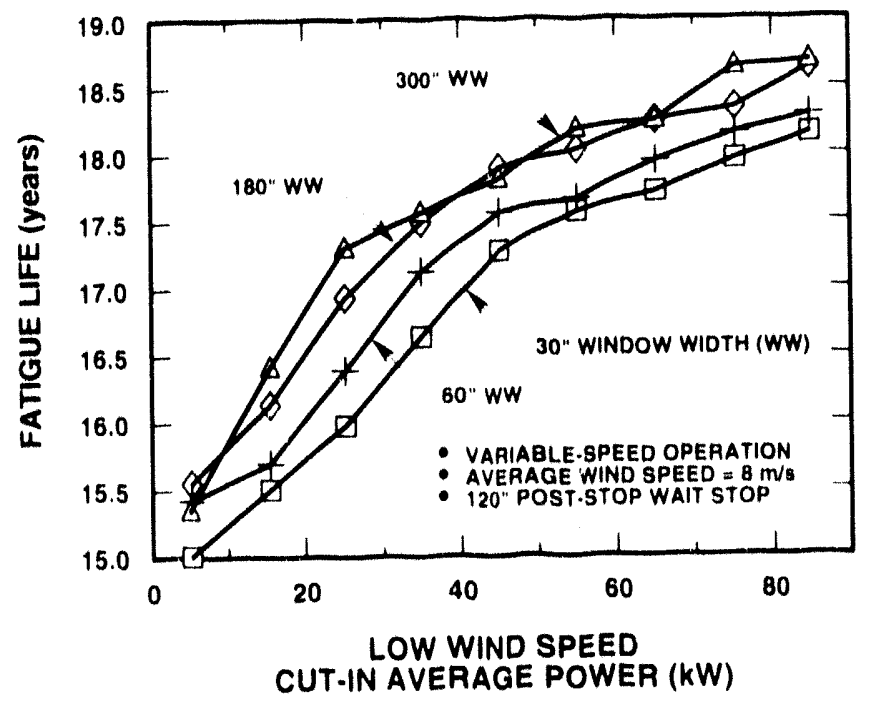

Figure 14. Variation in Fatigue Life as a Function of Low Wind Speed Cut-in Threshold for Various Settings for Moving Average Window Width, Assuming a PostStop Wait Time of 120 Seconds $(8-\mathrm{m} / \mathrm{s}$ Site $)$ 
- Moving average power threshold level: $55 \mathrm{~kW}$

- Moving average power window width: 300 seconds

- Post-stop wait time:

120 seconds

\subsection{ASYM CONTROL SEOUENCES FOR RPMS NEAR ROTOR CRITICAL SPEED RANGES}

This section will discuss various WT rotor speed control considerations when operating near rotor speeds that may excite critical structural resonances. Section 6 will provide results from simulations of various control approaches aimed at minimizing fatigue damage and actual time spent operating near critical rotor rpms.

\subsection{Damage Density and Rotor Speed Control}

The damage rate function (DRF) is the distribution of fatigue damage rate per cycle as either a function of wind speed or rotor rpm. Past studies, related to constantspeed WTs, have employed the DRF as a function of wind speed. The wind p: obability distribution function is convolved with the DRF to produce the damage distribution function (DDF). The DDF represents the distribution (i.e., a histogram) of fractional fatigue damage per year for each wind speed interval at the specific site studied. It is a bell-shaped curve with a maximum value that may occur for wind speeds above $22 \mathrm{~m} / \mathrm{s}$. The DDF is a useful function to aid in defining the high cutout wind speed for shutting down the machine to protect it from fatigue damage [6].

For a VSCF WT, the equivalent damage density distribution as a function of rpm (based on the desire to have the controller follow the operating envelope) is useful in evaluating the role of operation at various rotor speeds in consuming fatigue life. The basis of such a curve is the damage rate per cycle for operation at each rotor speed. Figure 15 is a plot of (1) typical damage rate values for the case of a wind stress function (WSF) of $0.28 \mathrm{RMS}(\mathrm{MPa}) / \mathrm{m} / \mathrm{s}(40 \mathrm{RMS}(\mathrm{psi}) / \mathrm{m} / \mathrm{s})$, and (2) the projection of the operating envelope on the power-rpm plane. Integer values of wind speed are labeled on the power curve. The WSF is the sensitivity of the rotor cyclic stress components (RMS value) at critically stressed joints to the input wind speed [6].

Figure 15 indicates that there are three critical speed ranges (CSRs) that may excite structural resonances. The lowest CSR, associated with a cable resonance, is centered at $23 \mathrm{rpm}$, and is modeled as having a "bandwidth" of plus or minus $1 \mathrm{rpm}$. The actual location of the mode will change slightly with temperature as the cable length and tension vary. This CSR for modal vibration is expected to lead to accelerated fatigue in components associated with the cable mount at the top of the rotor. The second CSR, for a "butterfly" or 1st edgewise mode, is generally centered at approximately $32 \mathrm{rpm}$. SNL tests have indicated that this mode will not be excited as long as the wind speed is less than $14 \mathrm{~m} / \mathrm{s}$ when the rotor is at this speed. Based on the curves shown in Figures 1 and 15 , the Test Bed should be operating at constant speed at $38 \mathrm{rpm}$ for wind speeds of 14 $\mathrm{m} / \mathrm{s}$ - and thus not excite this mode. The first edgewise mode will, however, receive brief excitation when the machine undergoes high wind speed shutdowns. During such periods, the machine is expected to be reducing speed at approximately $0.15 \mathrm{rpm} / \mathrm{sec}$, and will pass through the CSR in approximately 7 to 10 seconds. 


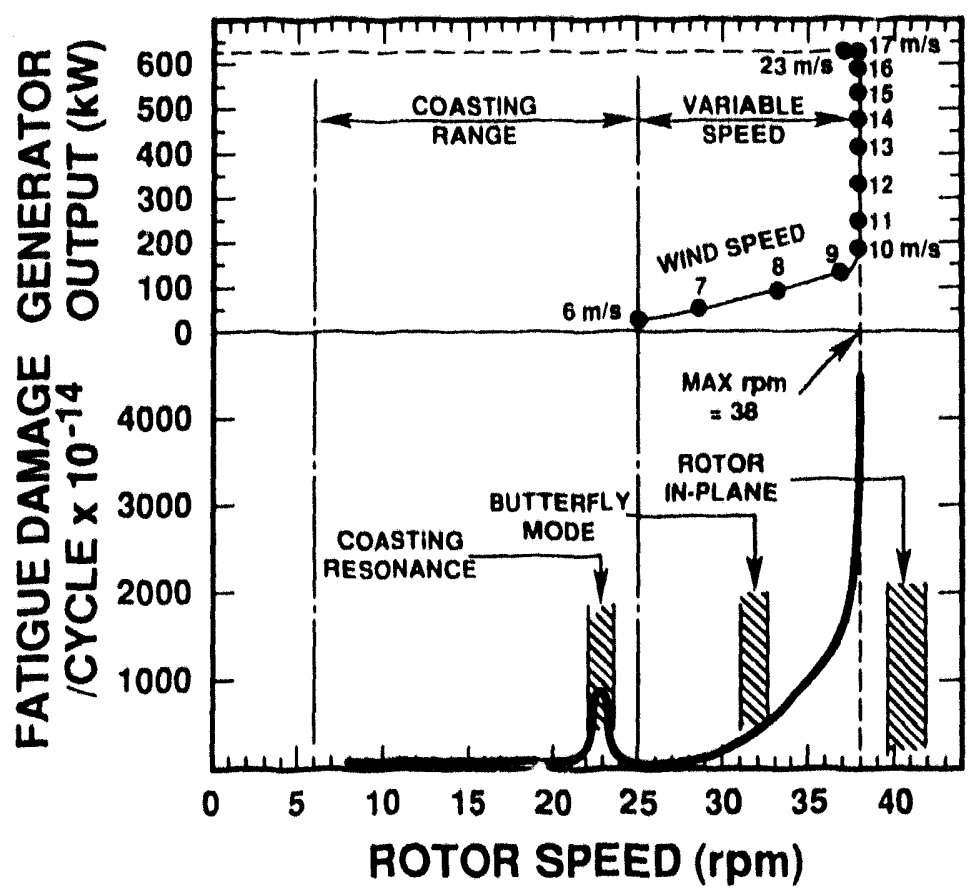

Figure 15. Variation of Test Bed Power Output and Fatigue Damage/Cycle vs. Rotor rpm

The third CSR is the tower in-plane noode located at rotor speeds between 39.5 and $42.0 \mathrm{rpm}$. Excitation of this mode must be avoided because of the potential of severe fatigue damage accumulation. Through the use of regenerative braking, the controller is expected to always keep the rotor $\mathrm{rpm}$ at values below approximately $38.5 \mathrm{rpm}-$ even in the presence of gusts.

\subsection{Speed Control Near Cable Resonance}

ASYM has been modified to control rotor speeds and minimize fatigue damage while operating near rotor speeds of $23 \mathrm{rpm}$. Figure 16, which is an expanded representation of the fatigue damage rate for speeds near $23 \mathrm{rpm}$, indicates that the fatigue damage rate is a relatively narrow-band phenomenon that has a "bandwidth", BW, that is half the total CSR of concern. A simple mathematical representation of the fatigue damage rate has been developed for operation in the CSR. The cable is assumed to respond in a manner similar to a lightly damped, second order dynamic system with a response amplitude described by the equation:

$$
G\left(\Omega_{R}\right)=\frac{A}{\left\{\left[1-\left(\Omega_{R} / \Omega_{n}\right)^{2}\right]^{2}+\left[2 \xi \Omega_{R} / \Omega_{n}\right]^{2}\right\}^{1 / 2}}
$$




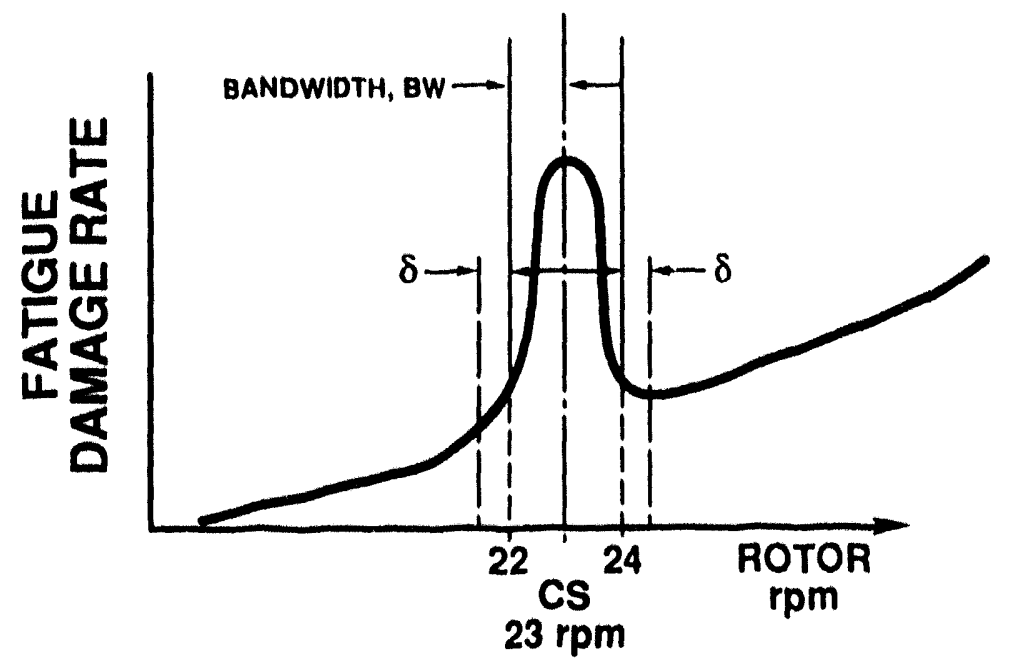

Figure 16. Representation of Fatigue Damage Rate in the Vicinity of a Critical Speed Range

where $\Omega_{R}$ is the rotor speed, $\Omega_{n}$ is the critical speed $(23 \mathrm{rpm}), \xi$ is the damping coefficient, and $A$ is an attenuation coefficient employed in ASYM to provide flexibility in adjusting the amplitude of the damage response. For rotor speeds between 22 and $24 \mathrm{rpm}$, equation (7) is employed by ASYM to describe the damage rate function. The added fatigue damage that results from operation within the CSR is added to the fatigue damage that results from normal operation (i.e., if no critical vibration modes are excited) to produce a total estimated fatigue damage for operation at each rpm interval within the CSR. The normal fatigue DRF that is associated with each stress cycle increases in a monotonic fashion with wind speed [12].

Although the true values for $A$ and $\xi$ are at present uncertain, for this writing their values have been assumed to be 0.5 and 0.001 respectively. This results in a relatively high multiplier of 250 for a rotor speed of $23 \mathrm{rpm}$, but only modest damage elsewhere within the CSR. This leads to a peak fatigue damage of 250 times greater than normal for operation within the CSR. These values are readily adjustable as new information is developed from ongoing SNL tests. Because the normal fatigue damage rate is very low for rotor speeds near $23 \mathrm{rpm}$, not a great deal of fatigue damage results from operation in this CSR. However, it is still a rotor speed range that should be avoided.

Figure 17 is a schematic diagram that represents the elements in the portion of the ASYM controller for operation near the CSR. The controller modulates rotor rpm for speeds that might excite a critical structural resonance centered at $23 \mathrm{rpm}$. WT control 


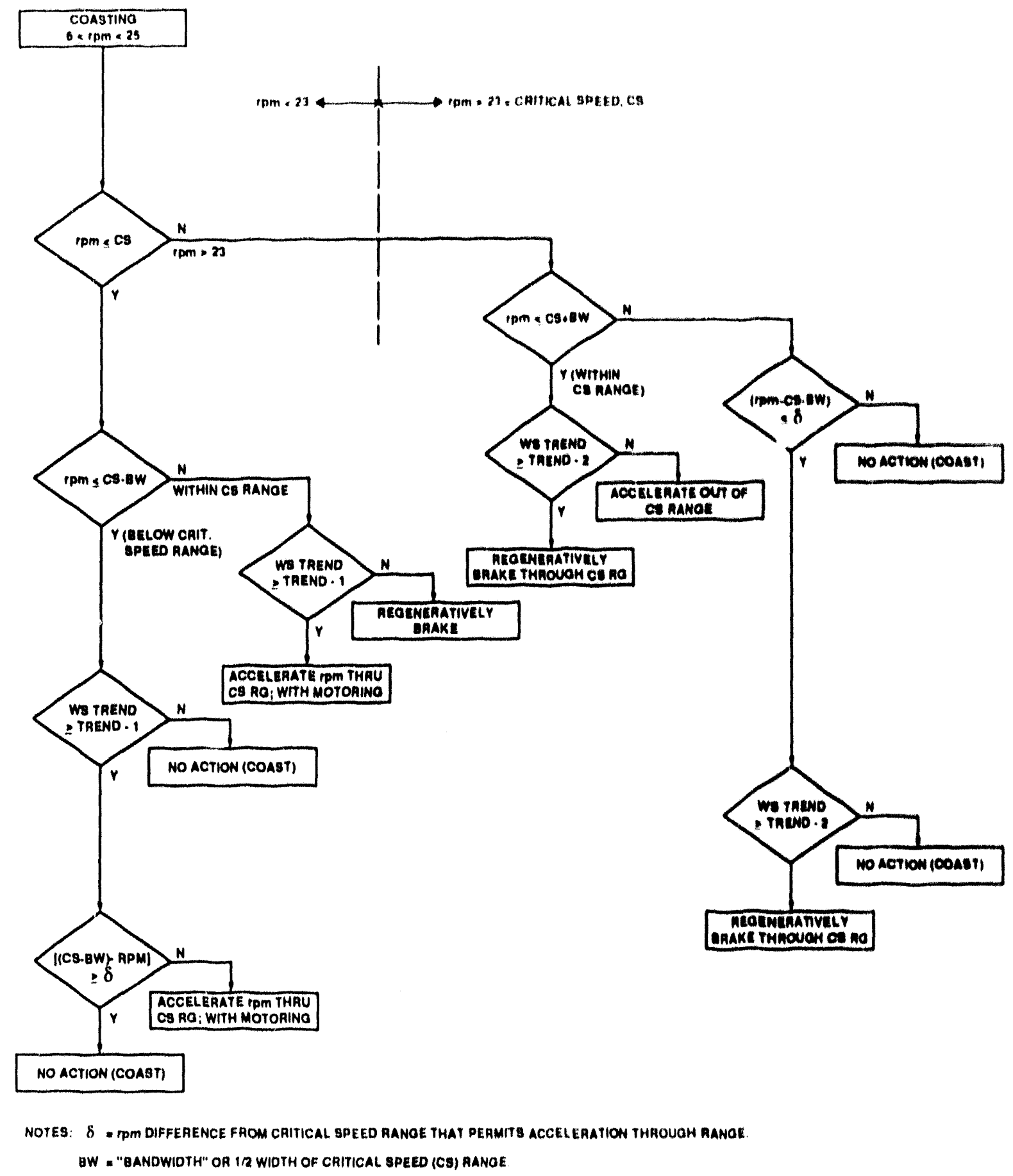

Figure 17. Schematic Diagram of Portion of ASYM Control Alogrithm for Control Near Critical Speed Ranges 
for rotor speeds close to $23 \mathrm{rpm}$ is expected to be in the coasting mode-producing zero net energy. Therefore, the speed of the rotor is governed only by the balance between the rotor torque applied by the wind and that applied by the drivetrain loads, described by modifying equation (1) as follows:

$$
P_{\text {rotor }} / \Omega_{R}=P_{G B} / \Omega_{R}+T_{C B}
$$

Because all spurious drivetrain torques are either constant or vary with rpm, the only controllable torque that is capable of modulating the rotor rpm is that from the generator, and it is not normally applied while the WT is coasting. However, for speed control it can be introduced as a positive torque (for rpm increases) or a negative torque (for rpm decreases) in equation (8). The former is a motoring torque and the latter is braking action that leads to positive generation (regenerative braking). Rotor accelerations, that are controlled hy modulating generator torque, are currently limited to $0.15 \mathrm{rpm} / \mathrm{s}$ in order to minimize the magnitude of transient torques introduced by the generator.

Reference to Figure 17 is useful in following the discussion on the control sequence below. While operating within the coasting speed range, the first controller decision is whether the rpm is above or below the critical speed (CS). Subsequently, the controller evaluates whether the rpm is within the "bandwidth" of the CSR, where fatigue damage is more severe. Whether the controller finds that the rotor rpm is within the band or not, it evaluates a wind speed trend criterion (discussed belnw). If the wind speed trend is satisfied, the speed of the rotor is altered to accelerate up through or down through the CSR. If the prior decision has determined that the rpm is within the CSR, the controller must take action to control rotor rpm so that it is in the CSR for a minimum time. Under such conditions, only if the trend criterion is satisfied will the rotor $\mathrm{rpm}$ be controlled to accelerate through the CSR.

If the wind speed trend is not satisfied, the WT regeneratively brakes to reduce rpm (if rotor speed is lower than the CS), or reduces generator torque (or motors if no positive power is being generated) to allow rotor rpm to increase to a value higher than the CSR (if rotor speed is initially higher than the CS). If the trend is not satisfied, and the speed is outside of the CSR, no control action is required and coasting continues. If, however, the wind speed trend is satisfied, and the rotor speed is outside of the CSR, the controller evaluates wheiher it still makes sense to accelerate through the CSR if the rpm is close enough to the boundary of the CSR to allow the controlled speed change to occur. The criterion for being close to the CSR boundary is defined as $\delta$ in Figures 16 and 17. A later section will discuss the merits of various trend levels and values for $\delta$.

\subsection{Wind Speed Trend}

A simple mathematical function has been developed to determine a crude trend in wind speed. The objective of employing a wind trend estimation is to minimize the number of times that the rotor rpm must cross through a CSR, thus minimizing associated fatigue damage. The trend measure currently employed in ASYM is the difference in two moving average wind speeds with different averaging periods. The long-term trend is determined by the wind speed averaged over a range of several minutes to 4 hours. A short-term trend is similarly calculated with a shorter averaging period. For the simulations discussed here, the averaging periods have been varied with ratios up to $18: 1$. 
If the short-term average exceeds the long-term average by a specified level, the wind speed trend is defined as positive. Based on satisfying a trend criterion for increasing wind speeds (i.e., Trend-1 in Figure 17), the controller will permit the rotor to speed up and cross through the CSR. Similarly, if the rotor speed is higher than the CSR, and the wind trend for decreasing wind speeds is sufficiently strong (i.e., Trend-2), the controller will regeneratively reduce the rotor rpm through the CSR.

\subsection{SIMULATION RESULTS FOR OPERATION NEAR CRITICAL SPEEDS}

\subsection{Controller Effectiveness in CSR}

To evaluate the effectiveness of the CSR controller portion of ASYM described in Figure 17, several simulations were carried out with different criteria for wind speed trend and $\mathrm{rpm}$ values for controller action. The measures of effectiveness are (1) operational time spent in the CSR, (2) associated fatigue damage from operation in the CSR, and (3) regenerative braking or motoring energy required to control rotor speed. Some of the key results are discussed below.

Damage Rate vs. RPM. Fatigue damage rates vary with either (1) the wind speed in general (irrespective of rotor speed) or (2) modal vibration within a CSR. To obtain a first-order estimate of the sensitivity of damage rate to rotor speed in a VSCF WT, the damage density function (vs. rpm) is developed and plotted in Figure 18. The figure, estimated for the case of a mean annual wind speed of $8 \mathrm{~m} / \mathrm{s}$ and a wind-stress function (WSF) of $0.28 \mathrm{RMS}(\mathrm{MPa}) / \mathrm{m} / \mathrm{s}(40 \mathrm{RMS}(\mathrm{psi}) / \mathrm{m} / \mathrm{s})$, indicates the two factors that lead to accelerated damage. Operation in the constant-speed range at $38 \mathrm{rpm}$ produces high fatigue damage, but is a necessary part of generating high power output. The fatigue damage for operation within the CSR is shown as a small fraction of the damage at higher rpm's, but the analytical estimate of structural response for operation within the CSR (centered at $23 \mathrm{rpm}$ ) is only an estimate based on equation (7) and assumptions described earlier. The actual response and associated damage may be far greater. The estimates in Figure 18 do not show the full effect of operation at high wind speeds at constant or variable rpm. These factors will be included in later project efforts.

RPM Distributions. Figure 19 is a plot of the results of simulations that compare the number of hours per year that the WT spends in various rpm bins over the whole operating envelope. The average wind speed condition and the cut-in algorithm criterion are listed above the figure. The baseline simulation is for the case of no active speed control during WT coasting (square symbols), and the other case is for the use of active "smart" controls with wind-trend filters specified in the figure. The CSR crossing criterion, $\delta$, that defines how close to the CSR boundary the actual rpm must be to initiate a crossing through the CSR, has been chosen as $0 \mathrm{rpm}$. It should be noted that for rotor speeds higher than $25 \mathrm{rpm}$, there appears to be no difference in the number of hours in each bin between the controlled and uncontrolled case. The major difference arises due to the CSR controller that affects the operation in low-rpm bins.

The key results of the simulation are summarized in Figure 20, which is an expanded-scale view of the plot for rotor speeds less than $25 \mathrm{rpm}$. The notes in the figure define the parameters of the control system in the CSR. In the order listed, these include 50-sec. medium-term and 150-sec. long-term wind speed trend moving average window 


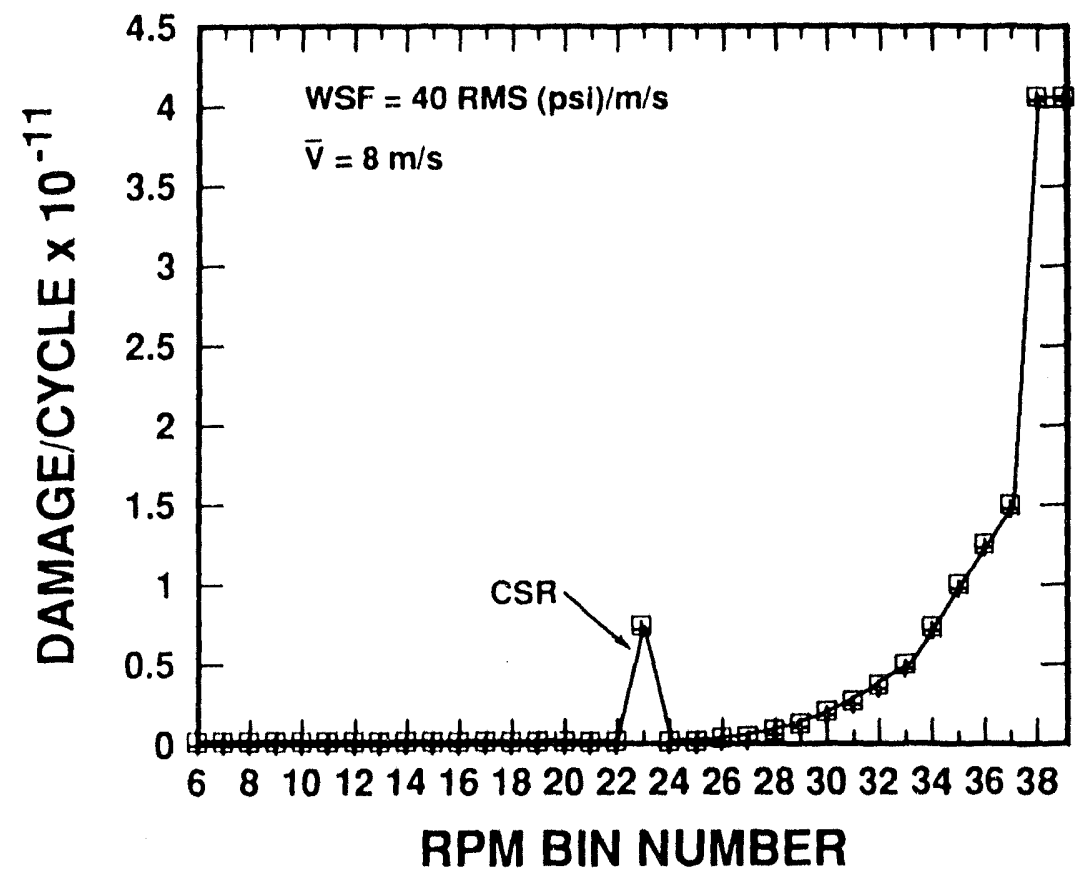

Figure 18. Test Bed Damage Density Function vs. rpm

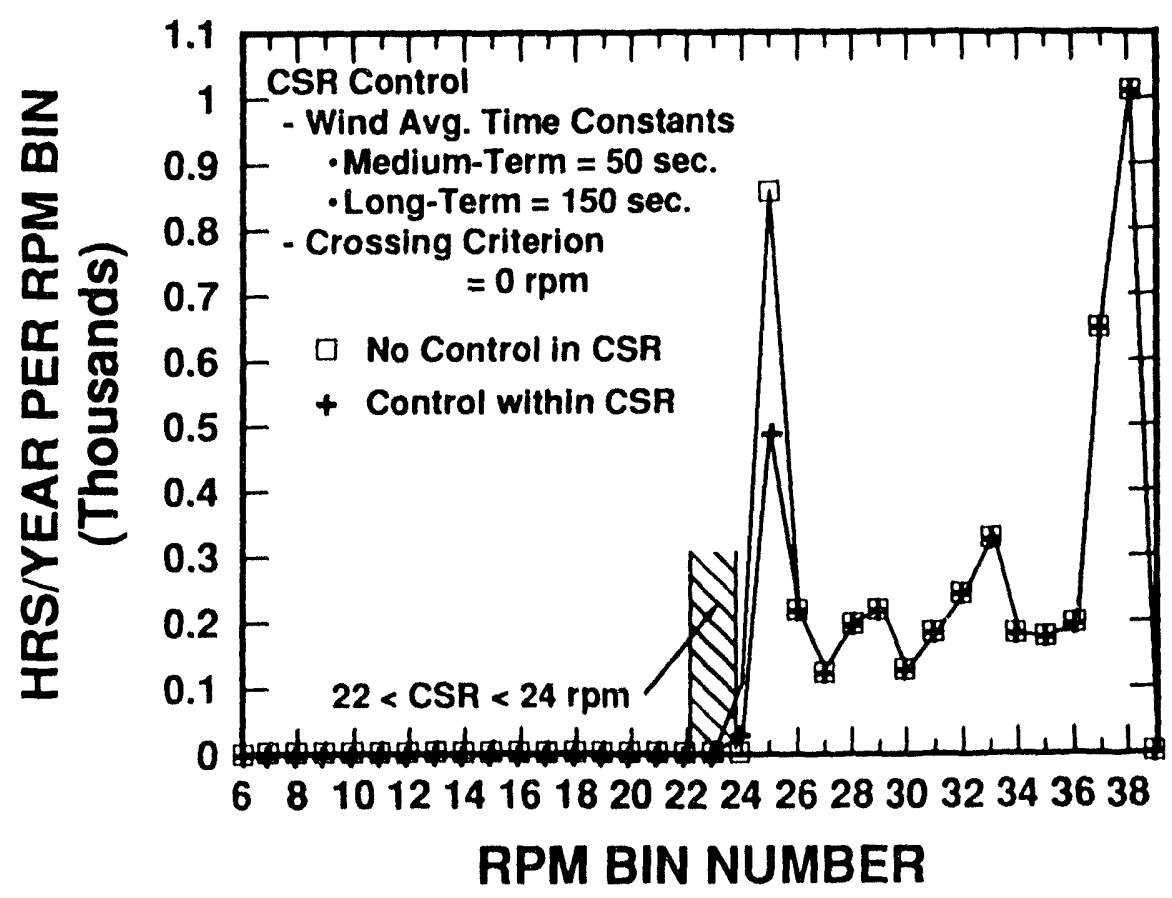

Figure 19. On-Time Distribution vs. rpm Bins 


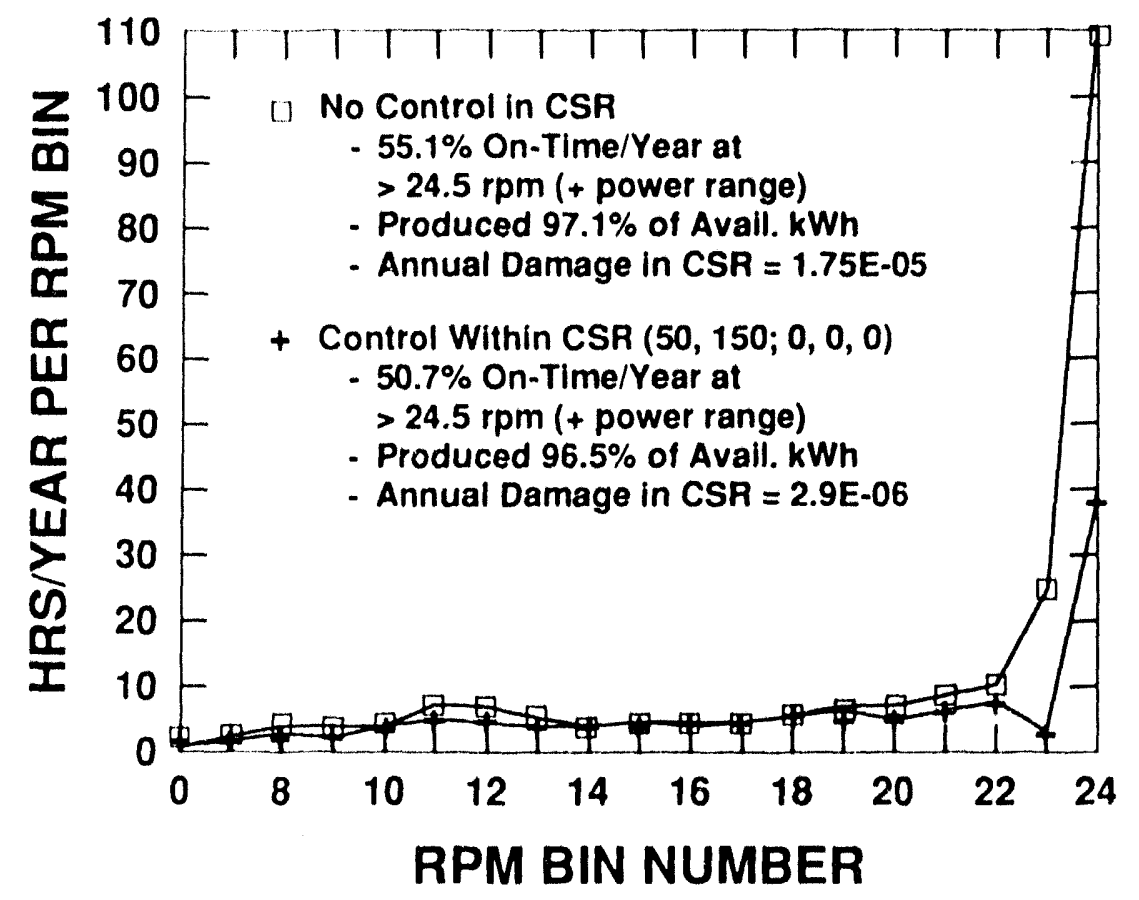

Figure 20. Test Bed Distribution of Dn-Time for rpms Less Than 25

time constants, values of $0 \mathrm{~m} / \mathrm{s}$ for the required values of the medium-term and long-term trends to permit the rotor rpm to cross through the CSR, and finally a 0 value for $\delta$, the difference between the actual $\mathrm{rpm}$ and that at the nearest boundary of the CSR. The energy production and damage results, also shown in Figure 20, indicate that for the case of no CSR control, the WT stays within the power-producing rotor speed range (i.e., $>25$ $\mathrm{rpm}$ ) approximately 5 percent more time than for the controlled case. Thus, it permits the machine to generate approximately $0.6 \%$ more energy. A detailed examination of the simulation results indicates that the major source for on-time variations is in the $25-\mathrm{rpm}$ speed bin. The case for no CSR speed control leads to approximately 6 times as much fatigue damage in the CSR. In each case studied, the fatigue damage estimated for operation in the CSR is less than one percent of the total fatigue damage for operation over the entire operating envelope. However, the results show the effectiveness of the control approach.

All cases that were studied employed a 10-second filter on the dynamic wind speed that is driving the rotor speed variations. The key parameters studied include (1) the operating time in the CSR, (2) associated fatigue damage when rotor speeds coincide with the CSR, and (3) regenerative and motoring energies. Regenerative braking and/or motoring energies were applied to bring about transient or short-term rotor speed corrections (limited to accelerations of $0.15 \mathrm{rpm} / \mathrm{s}$ ) to (1) move the rotor speed away from the CSR if the wind speed trend criterion was not satisfied, or (2) accelerate through the CSR if the rpm was within the CSR (or sufficiently close to the boundary) and the wind speed trend criterion was met. As discussed previously, regenerative braking energy is also produced when (1) the rotor speed is in excess of the envelope value shown in 
Figure 1 and (2) when the WT is stopped in an emergency manner from a high wind speed condition.

\subsection{Summary of Results for Control Near CSRs}

Summary Table. Table 1 is a summary of the key results from a series of simulations in which the effectiveness of control near the CSR was evaluated. The simulations explored the sensitivity of CSR control effectiveness to four key parameters. The table lists the various control parameters in the first four columns while the last two columns contain two significant measurements of the effectiveness of the control approaches. The fifth column summarizes the expected number of hours per year that the rotor rpm will be within $0.5 \mathrm{rpm}$ of the critical speed of $23 \mathrm{rpm}$. The sixth column lists the annual fatigue damage (after being multiplied by 1 million) that is expected to occur due to dwell time within the rotor speed range of 22.5 to $23.5 \mathrm{rpm}$.

The values for the medium-term moving average wind speed filter time constant, $\tau_{1}$, are listed in column 1 . The footnote to the table indicates that, for the estimates listed, all long-term moving average wind speed averages have filters with a time constant, 12, that are three times as long as the medium-term time constant. The second and third columns of the table are the wind speed trends (in units of $\mathrm{m} / \mathrm{s}$ ) that apply for increasing and decreasing rotor speeds, respectively.

The following example will illustrate the use of the parameters. For a condition in which the rotor $\mathrm{rpm}$ is less than the critical speed, $23 \mathrm{rpm}$, and the wind speed is increasing, the coasting rpm will also be increasing. As the rpm approaches the lower end of the CSR, the CSR controller will take over (see Figure 17). If WS-1 (column 2, Table 1) is set at $1 \mathrm{~m} / \mathrm{s}$, and WS-2 is set at $1 \mathrm{~m} / \mathrm{s}$ (i.e., the fourth row of results for the cases of dynamic rotor speed control) the medium-term wind speed would have to exceed the long-term wind speed by $1 \mathrm{~m} / \mathrm{s}$ to enable the rotor speed to accelerate up through the CSR. For the set of control parameters shown in the fourth case, the medium-term moving average wind speed is measured by a 5()-second average, and the long-term average is measured by a $15($ )-second average. Furthermore, the fourth column of control parameters identifies the value, $\delta$, shown in Figure 16, that is a measure of how close the rpm can be to the boundary of the CSR and still permit the rotor to accelerate through the CSR. In the case described, there is a zero permitted margin outside of the CSR for which a CSR crossing can be initiated.

Active Speed Control Within the CSR. The detailed results for the group of the five top rows for the actively controlled cases in Table 1 are plotted in Figure 21. The rows below the top five rows (under active control) in Table 1 are for cases in which the medium-term wind speed filter time constant or the rpm difference criterion, $\delta$, were varied 10 explore the sensitivity to each.

The results, shown in Figure 21 and listed in the top five rows of the portion of Table 1 that applies to dynamic rotor speed control, indicate the following:

(1) The rotor speed coincides with the CSR for a minimum number of hours per year if no wind speed difference between short and long-term averages is required for rotor speed increases, but that a wind speed trend of $1 \mathrm{~m} / \mathrm{s}$ is required for rotor speed decreases. This is the $(0,1)$ wind speed trend criterion 
Table 1. Tabular Results from Simulating "Smart" Controls for Operation Within the 23-rpm Rotor Speed Range

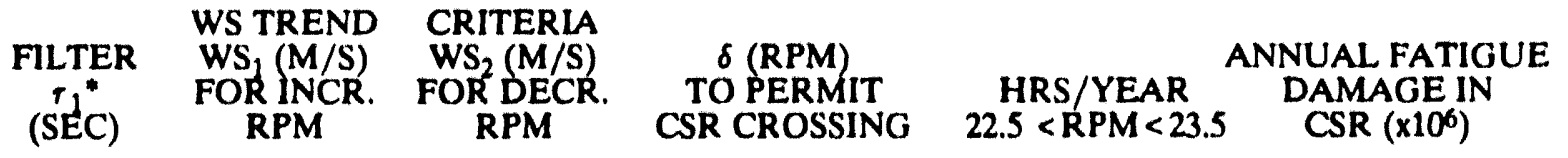

- NO DYNAMIC ROTOR SPEED CONTROL
0
0
0
0
24.22
17.5

- APPLY DYNAMIC ROTOR SPEED CONTROL

\begin{tabular}{|c|c|c|c|c|c|}
\hline $\begin{array}{l}50 \\
50 \\
50 \\
50 \\
50\end{array}$ & $\begin{array}{l}0 \\
1 \\
2 \\
1 \\
0\end{array}$ & $\begin{array}{l}0 \\
0 \\
0 \\
1 \\
1\end{array}$ & $\begin{array}{l}0 \\
0 \\
0 \\
0 \\
0\end{array}$ & $\begin{array}{l}3.00 \\
3.46 \\
7.85 \\
2.42 \\
2.30\end{array}$ & $\begin{array}{r}2.9 \\
2.9 \\
8.7 \\
26.2 \\
26.2\end{array}$ \\
\hline $\begin{array}{l}50 \\
50 \\
50 \\
50 \\
50\end{array}$ & $\begin{array}{l}0 \\
1 \\
2 \\
1 \\
0\end{array}$ & $\begin{array}{l}0 \\
0 \\
0 \\
1 \\
1\end{array}$ & $\begin{array}{l}0.2 \\
0.2 \\
0.2 \\
0.2 \\
0.2\end{array}$ & $\begin{array}{l}3.00 \\
3.44 \\
7.85 \\
2.40 \\
2.30\end{array}$ & $\begin{array}{r}2.9 \\
2.9 \\
8.7 \\
26.2 \\
26.2\end{array}$ \\
\hline $\begin{array}{l}100 \\
100 \\
100 \\
100 \\
100\end{array}$ & $\begin{array}{l}0 \\
1 \\
2 \\
1 \\
0\end{array}$ & $\begin{array}{l}0 \\
0 \\
0 \\
1 \\
1\end{array}$ & $\begin{array}{l}0.2 \\
0.2 \\
0.2 \\
0.2 \\
0.2\end{array}$ & $\begin{array}{l}3.26 \\
4.79 \\
5.56 \\
2.35 \\
2.14\end{array}$ & $\begin{array}{l}2.9 \\
5.8 \\
5.8 \\
5.8 \\
5.8\end{array}$ \\
\hline $\begin{array}{l}300 \\
300 \\
300 \\
300 \\
300\end{array}$ & $\begin{array}{l}0 \\
1 \\
2 \\
1 \\
0\end{array}$ & $\begin{array}{l}0 \\
0 \\
0 \\
1 \\
1\end{array}$ & $\begin{array}{l}0.2 \\
0.2 \\
0.2 \\
0.2 \\
0.2\end{array}$ & $\begin{array}{l}4.15 \\
5.37 \\
5.37 \\
2.32 \\
2.13\end{array}$ & $\begin{array}{r}5.8 \\
5.8 \\
5.8 \\
17.5 \\
17.5\end{array}$ \\
\hline
\end{tabular}

shown in Figure 21, and resulted in operation in the CSR for approximately 2.3 hours per year. The $(1,1)$ wind trend criterion produced similar results.

(2) There is substantially more fatigue damage associated with the control approach that produced the lowest dwell times in the CSR because during light winds the rotor speed is often dropping into the middle of the CSR. During such operation, the controller requires generator motoring (or reduced generator torque) to increase rotor speeds while it waits to satisfy the wind trend criterion for reducing rotor speeds. This conclusion is evident in the 


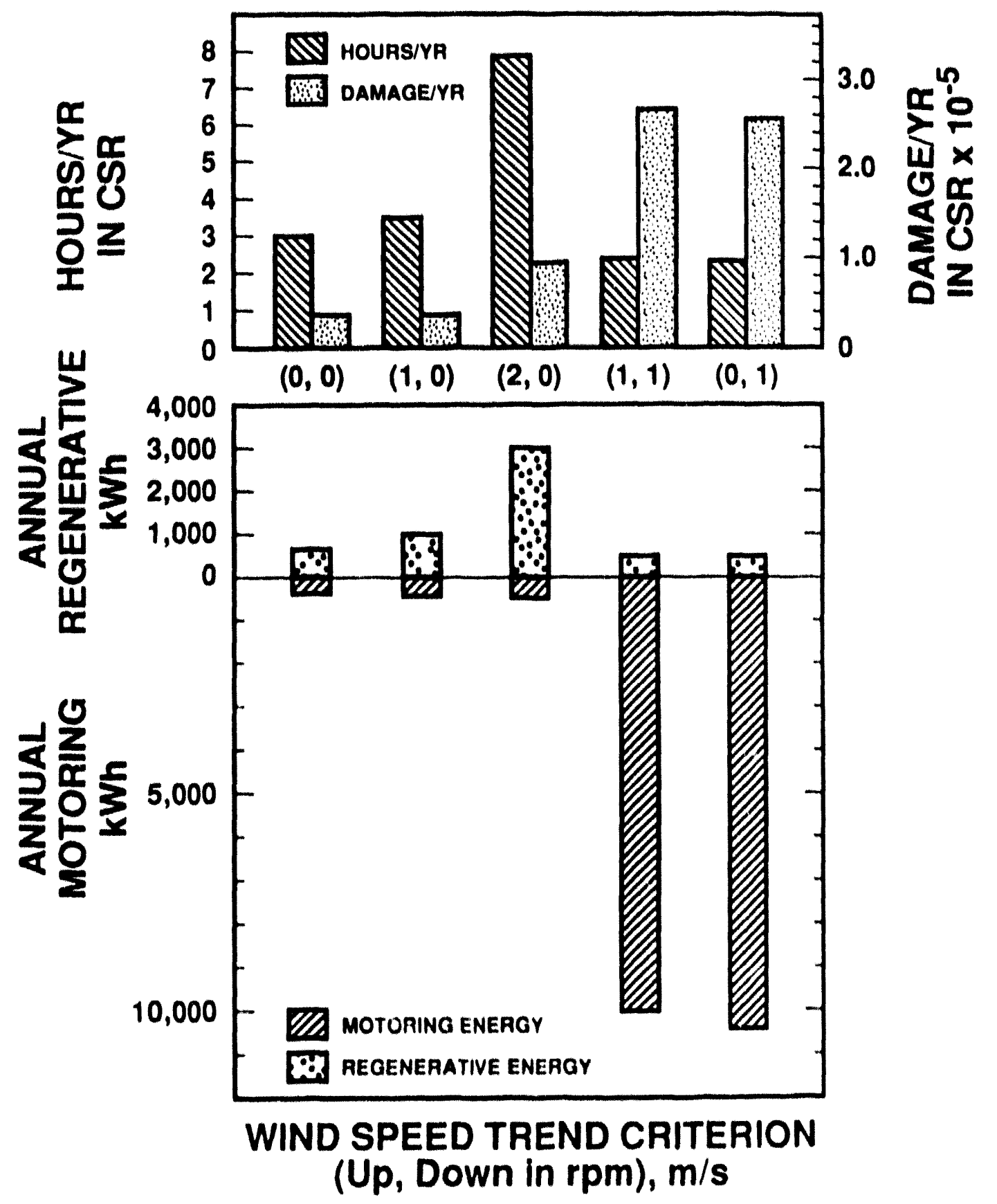

Figure 21. Summary of Key Measurements of Control System Effectiveness for Five Cases listed in Table 1 for $=50$ Seconds, $=150$ Seconds, and $=0 \mathrm{rpm}$ (First 5 cases Listed Under Dynamic Rotor Speed Control) 
high motoring energy required each year for the awo cases with minimum dwell time in the (Ske (sec boltom portion of lig. 21).

Another way to view this anomalous finding is described below. During a normal startiup seyuence, when the wind speed trend is sillisfied, the machine is motored up $1025 \mathrm{rgm}$. At this time, it is allowed on cither (1) coast down in speed if winds are dropping. or (2) begin generating uscful power at rpms ahove 25 if winds are sufficient. Thus, there is a preponderance of conditions where the rpmen is entering the (STR from speeds less than the (S ats opplosed 10 more than the ('S. If the comtroller establishes stringent guidelines for

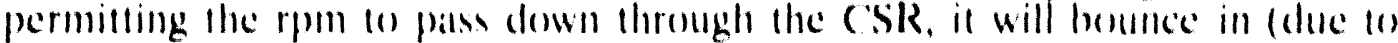
down gusts) and be molured out of the upper end of the (SSR freguently. Such

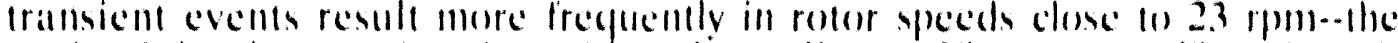
peak of the dambege function within the (SR (sece ligute lo). Therefore, it

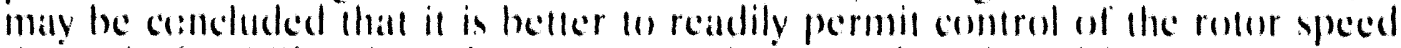
through the (STR when the roter speed appersatches the eritical speed range from higher values than lo hinder rpon reductions.

(3) The best balance of minimizing lime in the (SR and falligue damage is ansocialed with mo use of a wind speed trend. This is the (1),(1) criterion listed on the left portion of the figure. It should be noticed that this casse also produces the least braking of moloring as well. It indicalles that the dyulantic

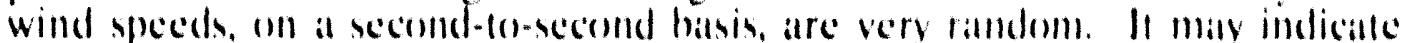
that the use of the wind filter for dynamic response of the ronger maty be all that

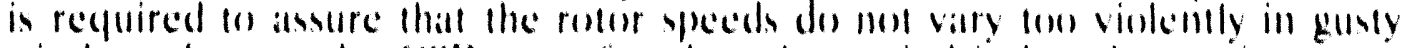

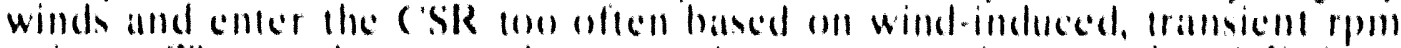

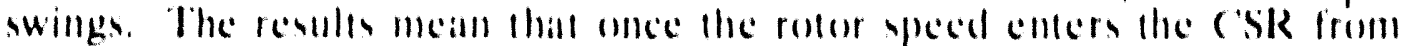
either lower or higher form, the speed combroller should take over and carry the rpm through the rathge is rapidly as permitted.

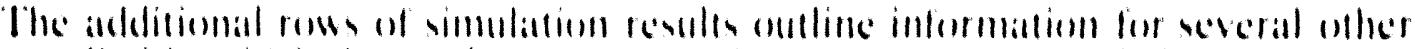

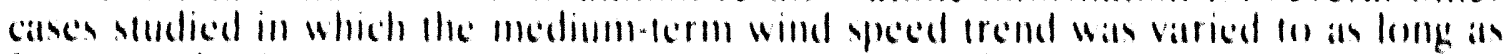

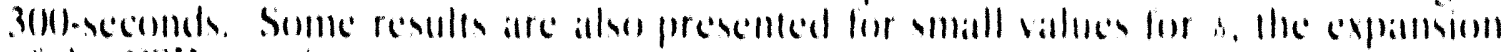
of the ( SSR crowing rimles.

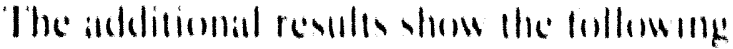

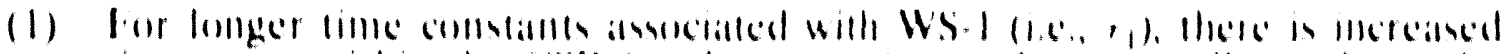

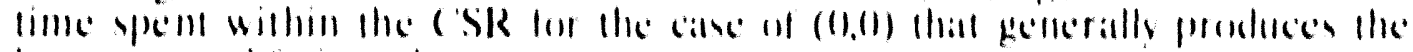

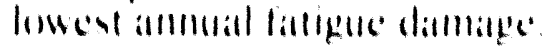

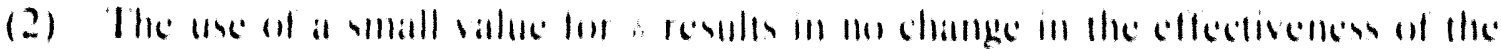

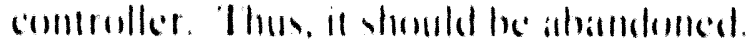

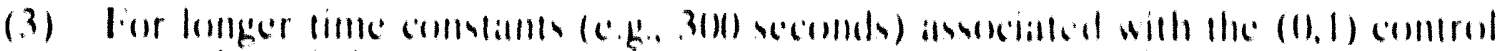

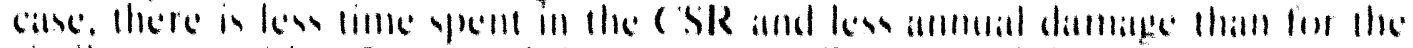

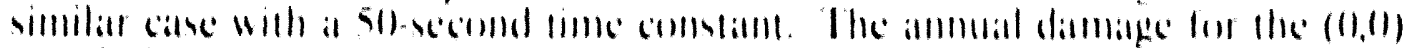

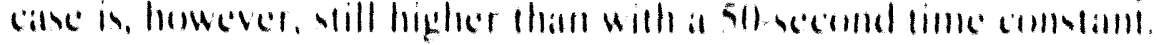

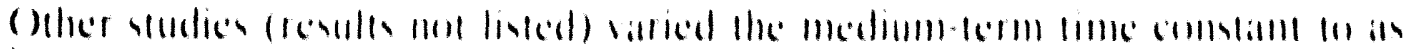

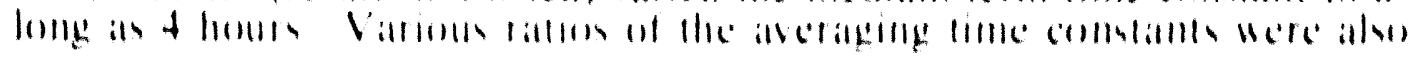


examined. The results were generally found to be consistent with those summarized in Table 1.

Comparison with No CSR Control. By examining the results in the table, the following conclusions can be drawn with regard to no dynamic speed control when operating within the CSR (i.e., top row of results):

(1) The use of no CSR speed control leads to over 24 hours of operating time in the CSR (a factor of 8 or 10 more than the time for the best controlled cases), but the associated annual fatigue damage is no worse than for the case of $(0,1)$ or $(1,1)$ wind speed criteria discussed above. Therefore, it appears that the controller is marginally useful for the damage rates studied here for the CSR, but could be substantially more valuable for CSRs that produce a great deal of fatigue damage.

(2) There appears to be no benefit in employing the rpm difference criterion, $\delta$, that effectively expands the range over which controller action can take place. because the time spent in the CSR, and any associated damage does not vary with the value of $\delta$.

(3) Longer wind speed averaging periods lead to longer times spent in the CSR for those cases that are the most appealing $[i . e .$, the $(0,0)$ and $(1,0)$ wind speed trend cases]. However, for the cases that have the least dwell time in the CSR, but high associated fatigue damage li.e., the $(1,1)$ and $(0,1)$ cases], the longer averaging periods lead to slightly less dwell time, but no change in the fatigue damage. Thus, it appears that the best approach is to use no wind speed trend criterion, but to exercise active rotor speed control when the rotor speed enters the CSR during coasting operation.

(4) The use of Markov chains to develop hourly average wind speeds provides a means of structuring the hour-by-hour average wind speeds to be correlated. However, any "persistence" that may be found in high frequency wind speed traces may not be properly taken into account in the application of the Shinozuka Method to develop wind speed dynamics (turbulence effects). Thus, the use of wind speed filters with different time constants may be an inappropriate way to develop trends if the second-by-second simulated wind speed data are truly random.

\section{1) CONCLUSIONS}

Based on the application of ASYM to the SNL 34-m VAWT Test Bed, the following conclusions can be drawn based on the findings discussed above:

(1) ASYM is a flexible and useful design tool for exploring control options to maximize energy production and minimize fatigue damage associated with a WT.

(2) Preliminary simulation results of low wind speed cut-in control variables for the SNI. 34-m Test Bed produce the following recommended controller sellings: 
- Moving average power threshold level:

- Moving average window width:

- Post-stop wait time:

$55 \mathrm{~kW}$

30() seconds

120 seconds

(3) The value of the CSR controller is demonstrated by the results that show that there are reduced operating time and fatigue associated with its application (see Table 1). It is also expected to be a useful tool for controlling braking action from high wind speeds, when the rotor rpm must pass through the rotor first edgewise vibration mode, and for control of rotor speed "overshoots" at 38 $\mathrm{rpm}$. While operating in the vicinity of the "corners" of the operating envelope at which control shifis from VSCF to the constant-speed mode at $38 \mathrm{rpm}$, the rotor speed may experience gust-induced rpm excursions that could cause the rotor speed to coincide with the first tower in-plane mode that begins at approximately $39.5 \mathrm{rpm}$. In this instance, the CSR controller will he invoked 10 reduce fatigue damage.

(4) The use of wind speed trends as a means of enhancing the effectiveness of the CSR controller appears to have no value in conjunction with the ASYM code. Preliminary studies indicate that once the rotor rpm coincides with a CSR, the controller should take action to bring the rpm to the wher side of the CSR.

(5) There appear to be no henefits from beginning a traverse through the CSR when an rpm difference criterion is met (when a wind yped irend is also met). Thus, simpler controls produce the best results for the cases sludied. For CSRs that have a hroader rotor speed range, and the potential for more severe fatigue damage, the more sophisticated speed controls may still he warranted.

\section{X.1) BLELRLNCLS}

1. Hinrichene, E. N. "Integration of Wind Turbine and Power System Controls," Sixth Biennial Wind Energy Conference and Workshop, Minnesipolis. MN, June 1-3, 1083. American Solar Energy Suciety, Boulder, CO.

2. Me Nerney, (i. M., "Control Algorithm Inventigations," Pros: of Vintical-Aan Wims

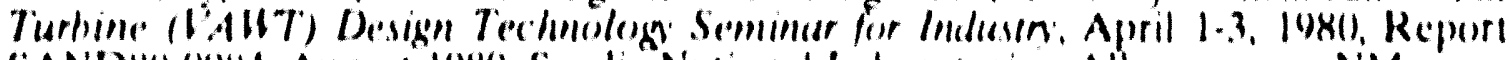
SANDB().(1)St, August 198(), Sandia National I ahoraluries, Albuguerque, NM

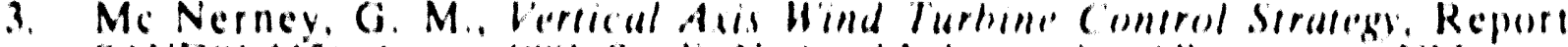

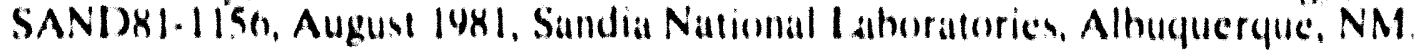

4. Me Nernes, (i. M., and Veers, P. S. A Murkow Merthonl for Simulating Nom- Cinusumen

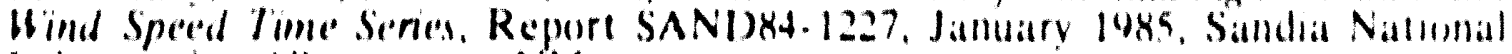
Iaboratories, Alhuquerque, NM.

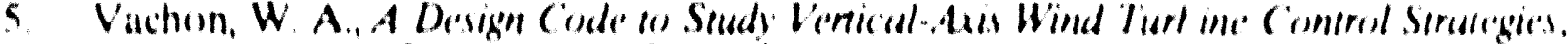
Report SAN1 )87.7012. July 1987. Sandia National I aboratories, Albuquerque, NM.

h. Vachon, W. A. "The leflects of Control Algormhm, on Fatigue I ife and I:nergy Production of Vertical Axis Wind Turbines," Sevemin ASMI. Wind Inergy Symposium, New Orleans, I.A, January 10.13, 148K, 121. 144.158. 
7. Kaimal, J. C., Wyngaard, J. C., Izumi, Y., and Cote, O. R., "Spectral Characteristics of Surface Layer Turbulence," Quart. J. Roy. Meteorol. Soc., 28, pp. 563-589.

8. Kaimal, J. C., Gaynor, J. E., and Wolfe, D. E., Turbulence Statistics for Design of Wind Turbine Generators, NOAA/ERL Wave Propagation Laboratory, Boulder, CO, Report to DOE Under Interagency Agreement No. DE-A106-79ET23115, December 1980.

9. Frost, W., Long, D. H., and Turner, R. E., "Engineering Handbook on the Atmospheric Environment Guidelines for Use in Wind Turbine Generator Development," NASA Technical Paper Number 1359, December 1979.

10. Veers, P. S., Modelling Stochastic Wind Loads on Vertical Axis Wind Turbines, Report SAND83-19(19, September 1984, Sandia National Laboratories, Albuquerque, NM.

11. Shinozuka, M., "Simulation of Multivariate and Multidimension Random Processes," J. of the Acrustical Society of America, V. 49, No. 1, (Part 2), 1957, p. 357.

12. Veers, P. S., A General Method for Farigue Anulysis of Venical Axis Wind Turbine Blades, Report SAND82-2543. October 1983, Sandia National Laboratories, Albuquerque, NM.

13. Miner, M. A.. "Cumulative Damage in Fatigue," ASME J. of Applied Mechanics, 67:A159.A164, 1945.

14. Sutherland, H. J., Ashwill, T. D., and Slack, N., The LIFE Computer Code Fatigue Life Prediction for Ventical Axis Wind Turbine Components, Report SAND87-(1)792, August 1987. Sandia National Laboratories, Albuquerque. NM.

15. Schluter, L. L.. and Sutherland, H. J., Reference Manual for the LIFE2 Computer Codc, Report SAND84.1396, September 1989, Sandia National Laboratories, Albuguerque. NM.

16. Vachon, W. A., "The Effects of Controls on Life and Energy Production of the 34-m VAWT Test Bed," Bih ASME Wind Energy Symposium, Houston, TX, January 22.25, 1989, pp, 2(19.218.

17. Vachon, W. A., "Smart Control Algorithms for Operation of Variable-Speed Wind Turbines," Ninth ASME Wind Energy Symposium. New Orleans, LA, January 14-17. pp. $191.2(10)$.

18. Kalph, M. F... "Control of a Variable-Speed Generator on the Sandia 34-Metre Verlical Axis "Wind Turbine," Proc: of AlVEA/DOE Wimdpower $8 \%$. San Francisco. (A, September 24-27, 1989, pp. 99.114.

19. Rulph, M. E., "A Model of the 34-m VAWT Variable Speed Cenerator Control System," ASME Ninth Wind Energy Symposium, New Orleans, LA, January 14-17. $1990, \mathrm{pp} .189 .190$. 
20. Carne, T. G. et al., "Modal Validation of the Sandia 34-Meter Test Bed Turbine Using Substructured Modal-Testing," 8th ASME Wind Energy Symposium, Houston, TX, January 22-25, 1989, pp. 277-283.

21. Ashwill, T. D., and Veers, P. S., "Structural Response Measurements and Predictions for the Sandia 34-Meter Test Bed," Ninth ASME Wind Energy Symposium, New Orleans, LA, January 14-17, 1990, pp. 137-144.

22. Ashwill, T. D., Initial Structural Response Measurements and Model Validation for the Sandia 34.m VAWT Test Bed, Report SAND88-0633, February 1990, Sandia National Laboratories, Albuquerque, NM. 


\section{DISTRIBUTION}

D. K. Ai

Alcon Technical Conter

Aluminum Company of America

Alcoil Cenler, PA 1.5069

R. E. Akins

Washington \& Lec University

P.O. Box 7.35

Lexinglon, VA 24450)

M. Anderson

Rencwable Energy Systems, Lid.

Eaton Court, Maylands Avenue

Hemel Hempstead

Herts HP2 7DR

ENGILAND

M. P. Ansell

School of Material Science

University of Ballh

Claverton Down

Bath BA2 7AY

Avon

ENGILAND

H. Ashley

Dept. of Acronaulics and

Astronaulics Mechanical Engr.

Slanford Universily

Stantord. CA 94.305

k. Bergey

University of Oklahoma

Acro Enginecring Department

Normall, OK 73069

\section{J. Bcurskens}

Programme Manager for Rencwable Energies

Nelherlands Energy Research

Foundation ECN

Westerduinweg 3

P.O. Box 1

1755 ZG Pellen (NH)

THE NETHERLANDS

J. R. Birk

Electric Power Rescarch Institute 3412 Hillview Avenue

Pilo Allo. CA 94304
N. Buller

Bomneville Power Administration

P.O. Box 3621

Porlland. OR 97208

C. P. Bulterficld

NREL.

1617 Cole Boulevard

Golden $\operatorname{CO} 8(140)$

R. N. Clark

USDA

Agricultural Research Service

Bushland, TX 79012

C. Coleman

Northern Power Systems

Box 6.59

Morelown, VT (0.5660)

O. de Vries

National Acrospace Laboratory

Anthony Fokkerweg 2

Amsterdam 1017

THE NETHERLANDS

E. A. DeMeo

Electric Power Research Institute

3412 Hillview Avenue

Palo Allo, CA 943014

J. B. Dragt

Institute for Wind Energy

Facully of Civil Engincering

Delfi Universily of Technology

Slevinweg 1

2628 C N Delft

THE NETHERLANDS

O. Dyes

Wind/Hydro/Ocean Div.

U.S. Department of Energy

I $(X X)$ Independence Avenue, SW

Washinglon, DC 20.585
A. J. Eggers. Jr.
RANN, Inc.
260) Sheridan Ave.. Suite 414
Palo Alto CA 94306
D. M. Egglesion
DME Engineering
P.O. Box 59(1)
Midland, TX 797(14-.59(17 
J. Eicrux

PR No. 5

Bolton, Ontario L.7E SSI

CANADA

R. A. Cialbraith

Dept. of Acrospace Enginecring

James Wall Building

University of Cilasgow

Cilasgow 012802 ;

SCOTL.AND

A. D. Ciarrad

Garrad Hasson

9-11 Saint Stephen Streel

Bristol BSI IEE.

ENCILAND

P. R. Cioldman

Wind/Hydro/Ocein Division

U.S. Department of Energy

10X) Independence Avenue

Washington, DC 201585

I. J. Grahaum

Dept. of Mechanical Enginecring

Southern Universily

P.O. Box 9445

Ballon Rouge. LA 7()813.944.5

G. Circegorek

Acronautical \& Astronauticial

Dept.

Ohio State Universily

230) West Case Roid

Columbus. (OH 43220

N. D. Ham

Acro/Astro Dept.

Massachusedts linstifute of

Technology

77 Massachusclls Avenuc

Cambridge. MA (12139)

L. Holling

Librarian

Nittional Alomic Muscum

Albuquerque. NM 8718.5

T. Hillesland

Pacific Cas and Electric Co.

340) Crow Canyon Road

San Ramon. CA 94.583
E. N. Hinrichsen

Power Technologies. lice.

P.O. Box 10.58

Schenectidy, NY 123011-1058

S. Hexk

Wind Energy Program

NREL.

Boulder ( $(0)$ 8(1)4(1)1

W. E. Holley

U.S. WindPower

69)52 Preston Avenue

Livermore. CA 94.550)

M. A. Ilyan

Pacilic Gias and Electric (oo.

$34(x)$ Crow Canyon Rond

SaII Rammon. ('A 945\%3

K. Jacksull

Dynimic Design

123 C Sired

Davis. ('A 95016

(). Krauss

Division of Engenecring Rescurch

Michigan State Universily

East Lamsing. MI 48525

V. Lilcey

Indal Techomolegiess line

3570 llawkenterie Reand

Misvissallual. Onlario 1.50 2VX

('ANAI)A

A. L.alleville

Fiacully of Applied Sicience

Uiliversilly of Sherbroxike

Sherbrooke. Quetexe JIK 2RI

CANAIAA

(i. Ci. L.cight

Now Mexico Finguneromy

Rescierch linstilute

(:ampus P.(). Bux 29

Alluqueryue, NM $\times 7131$

L. K. Liljegren

120 East PerIII Sired

Sall Dimas. CA 91773 
R. R. Loose, Director Wind/Hydro/Occan Division U.S. Department of Energy 1000 Independence Ave., SW Washington. DC 20585

R. Lynctle

R. Lynelle \& Assoc.. Inc. 15042 NE 40th Street

Sulic 206

Redmond. WA 98052

P. H. Madsen

Riso Natiomal Laboralory

Postbox 49

DK-4(OO) Roskilde

DENMARK

D. Malcolm

R. Lynelle \& A.ssociales. Inc.

15(1)2 N.E. 40) Street. Sulte 2(K)

Redmond. WA 980.52

J. F. Mandell

Momtana Stitc University

302 Cathleigh Hall

Bucman. MT 59717

B. Nasse

Institut de Recherche d'Hydro-Quebec

IX(K). Montec Sic-Julie

Varemnes. Quchec J3X ISI

CANADA

G. MiNerney

U.S. Windpower. Inc.

6952 Preston Avenue

Livermore. (A 9455)

R. N. Meroncy

Dept of Civil Enginecring

Colorado State Universily

Fort Collins. CO 801521

R. H. Monrex

Gougeon Brothers

I(x) Pallerson Avenue

Bay Cily. Ml $487(k)$

D. Morrison

New Mexico Engincering

Research Insillute

C:mpus P.O. Box 25

Albuquerque. NM 87131
V. Nelson

Department of Physics

West Texas State University

P.O. Box 248

Canyon, TX 79016

G. Nix

NREL

1617 Cole Boulevard

Golden, CO 80401

J. W. Oler

Mechanical Engineering Dept.

Texas Tech University

P.O. Box 4289

Lubbock, TX 79409

D. I. Page

Energy Technology Support Unit

B 156.7 Harwell Laboratory

Oxfordshire. OKII ORA

ENGILAND

C. Paquelle

The American Wind Energy Association

777 N. Capitol Street. NE

Suite 80.5

Washington. DC 2000)2

I. Paraschivoiu

Dept. of Mechanical Engineering

Ecole Polytecnique

CP $6(1) 79$

Succursale A

Montreal. Quetec H3C 3A7

CANADA

T. F. Pedersen

Riso Natlonal Laboratory

Posthox 49

DK-4(K) Roskilde

DENMARK

H. Petersen

Riso National Lalkoratory

Postbox 49

DK-4(X)) Roskilde

DENMARK 
R. G. Rajagopalan

Acrospace Enginecring Department

Iowa State Universily

404 Town Engincering Bldg.

Ames. IA 50)(11

R. Rangi

Manager, Wind Technology

Dept. of Energy. Mines and Resources

580 Boolh 7lh Floor

Ollawa. Ontario KIA OE4

CANADA

M. G. Real, Presidem

Alpha Real Ag

Feldeggstrasse 89

CH 8008 Zurich

SWITZERLAND

R. L. Scheffler

Research and Development Dept.

R(x)m 497

Southern California Edison

P.O. Box 8(K)

Roscmead, CA 91770

L. Schicubein

Batlelle-Pacilic Northwest Laboratory

P.O. Box 999

Richland, WA 993.52

T. Schweizer

Princelon Economic Research. Inc. 12300 Twinbrook Parkway

Suile 6.50

Rockville, MD 2()8.52

D. Sharpe

Dept. of Acronautical Engineering

Queen Mary College

Mile End Road

London, EI 4NS

ENGLAND

J. Sladky. Jr.

Kinctics Group, lnc.

P.O. Box 1071

Mercer Island. WA 98(1)40

M. Sinyder

Acro Engineering Department

Wichita Slate Universily

Wichila, KS 67208
L. H. Soderholm

Agricultur: Enginecring

$\mathrm{R}(\mathrm{k}) \mathrm{m} 21.3$

Iowa State University

Ames, IA 50010

P. South

I00) Castle Hill Crescent

Apt. 1006

Ottawa, Ontario K2C 3L6

CANADA

W. J. Siccley

Pacific Gas and Electric Co.

3400) Crow Canyon Road

San Ramon, CA 94583

F. S. Stoddard

Second Wind, Inc.

7 Davis Square

Somerville, MA (02144

D. Taylor

Alternative Energy Group

Wallon Hall

Open University

Milton Keynes MK7 6AA

(INITED KINGIDOM

G. P. Tennyson

DOE/AL/ETD

Albuquerque. NM 87115

W. V. Thompson

410 Eric wood Court

Manteca. CA 95336

R. W. Thresher

NREL

1617 Cole Boulcvard

Golden, CO 80401

K. J. Touryan

3701 Hawkins Streel. NE

Albuquerque, NM 87109-4512

W. A. Vachon

W. A. Vachon \& Associates

P.O. Box 149

Manchester. MA 01944 
P. Villecoy

Facully of Applied Science

University of Sherbroke

Sherbrooke, Quchec J|K 2RI

CANADA

T. Watson

Canadian Standards Associalion

178 Rexdale Boulevard

Rexdale, Ontario M9W IR.

CANADA

L. Wendell

Battelle-Pacilic Northwest

Laboratory

P.O. Box 999

Richland, WA 993.52

W. Wentz

Acro Engineering Department

Wichila State Universily

Wichila, KS 67208

R. E. Wilson

Mechanical Engineering Dept.

Oregon State University

Corvallis, OR 97331

M. Zuteck

MDZ Consulting

931 Cirove Streel

Kemah, TX 77.565

$\begin{array}{ll}14.34 & \text { C. Dohrmann } \\ 1434 & \text { D. W. Lobitz } \\ 1434 & \text { D. R. Martinez } \\ 1511 & \text { G. F. Homicz } \\ 1552 & \text { J. H. Strickland } \\ 1561 & \text { J. G. Arguello } \\ 1561 & \text { H. S. Morgan } \\ 1562 & \text { E. D. Recdy } \\ 2741 & \text { T. J. Baca } \\ 2741 & \text { T. G. Carne } \\ 2741 & \text { G. H. James III } \\ 2741 & \text { J. P. Lauffer } \\ 6214 & \text { H. M. Dodd (50) } \\ 6214 & \text { T. D. Ashwill } \\ 6214 & \text { D. E. Berg } \\ 6214 & \text { D. P. Burwinkle } \\ 6214 & \text { M. A. Rumsey } \\ 6214 & \text { L. L. Schluter } \\ 6214 & \text { H. J. Sutherland } \\ 6214 & \text { P. S. Veers } \\ 7141 & \text { Technical Library (5) } \\ 7151 & \text { Technical Publications } \\ 7161 & \text { J. C. Clausen } \\ 7613-2 & \text { Document Processing (10) } \\ & \text { For DOE/OSTl } \\ 8.523-2 & \text { Central Technical Files }\end{array}$

14.34

1434

1511

1.552

1561

1561

2741

2741

2741

2741

6214

6214

6214

6214

6214

6214

7141

7151

7161

8.523-2 Central Technical Files 

